\title{
Vascular Smooth Muscle Cell Senescence Promotes Atherosclerosis and Features of Plaque Vulnerability
}

\author{
Running title: Wang et al.; VSMC senescence in atherosclerosis \\ Julie Wang, PhD*; Anna K. Uryga, PhD*; Johannes Reinhold, MD; Nichola Figg; \\ Lauren Baker; Alison Finigan; Kelly Gray, PhD; Sheetal Kumar; Murray Clarke, PhD; \\ Martin Bennett, MD, PhD
}

Division of Cardiovascular Medicine, University of Cambridge, Addenbrooke's Hospital, Cambridge, United Kingdom

*contributed equally

\section{Address for Correspondence:}

Martin Bennett, $\mathrm{MD}, \mathrm{PhD}$

Division of Cardiovascular Medicine

University of Cambridge

Box 110, ACCI, Addenbrooke's Hospital

Cambridge, CB2 2QQ United Kingdom

Tel: $(+44) 1223331504$

Fax: $(+44) 1223331505$

E-mail:mrb@mole.bio.cam.ac.uk

Journal Subject Terms: Mechanisms; Smooth Muscle Proliferation and Differentiation 


\section{Abstract}

Background -Although vascular smooth muscle cell (VSMC) proliferation is implicated in atherogenesis, VSMCs in advanced plaques and cultured from plaques show evidence of VSMC senescence and DNA damage. In particular plaque VSMCs show shortening of telomeres, which can directly induce senescence. Senescence can have multiple effects on plaque development and morphology; however, the consequences of VSMC senescence or the mechanisms underlying VSMC senescence in atherosclerosis are mostly unknown.

Methods and Results-We examined expression of proteins that protect telomeres in VSMCs derived from human plaques and normal vessels. Plaque VSMCs showed reduced expression and telomere binding of Telomeric repeat-binding factor-2 (TRF2), associated with increased DNA damage. TRF2 expression was regulated by p53-dependent degradation of TRF2 protein. To examine the functional consequences of loss of TRF2, we expressed TRF2 or a TRF2 functional mutant (T188A) as either gain or loss of function studies in vitro and in $\mathrm{ApoE}^{-/-}$mice. TRF2 overexpression bypassed senescence, reduced DNA damage, and accelerated DNA repair, whereas TRF2 ${ }^{188 \mathrm{~A}}$ showed opposite effects. Transgenic mice expressing VSMC-specific $\mathrm{TRF}^{\mathrm{T} 188 \mathrm{~A}}$ showed increased atherosclerosis and necrotic core formation in vivo, whereas VSMC-specific TRF2 increased relative fibrous cap and decreased necrotic core areas. TRF2 protected against atherosclerosis independent of secretion of senescence-associated cytokines. Conclusions-We conclude that plaque VSMC senescence in atherosclerosis is associated with loss of TRF2. VSMC senescence promotes both atherosclerosis and features of plaque vulnerability, identifying prevention of senescence as a potential target for intervention.

Key words: atherosclerosis; vascular disease; smooth muscle; senescence 
Proliferation of vascular smooth muscle cells (VSMCs) is a central axiom of most models of atherosclerosis, promoting atherogenesis as a 'response to injury" ${ }^{1}$ or inflammation ${ }^{2}$. However, most heart attacks are caused by rupture of a 'vulnerable' plaque with a thin VSMC-poor fibrous cap overlying a relatively large necrotic core ${ }^{3,4}$. Plaque repair requires VSMC proliferation, and is thus beneficial at this stage. However, VSMCs from advanced human plaques show poor proliferation and premature senescence in culture ${ }^{5}$ and in $v i v o^{6}$; furthermore, fibrous cap VSMCs show extensive DNA damage, marked telomere shortening, and markers of senescence ${ }^{7}$. Although these findings suggest that VSMC senescence may be important in atherogenesis, its mechanisms and direct consequences are unproven.

\section{Replicative cell senescence is mediated in part by telomeres, which shorten during} replication and ultimately trigger a DNA damage response (DDR) and growth arrest. Telomeres comprise tandem DNA repeats that are maintained in a compact T-loop structure by the shelterin complex of telomere-associated proteins, including TRF1, TRF2, POT1, TIN2, RAP1 and TPP1. Shelterin proteins restrict access to telomerase and exonucleases/ligases, thus avoiding inappropriate telomere elongation and shortening respectively, and prevent exposure of chromosome ends that are recognised as double-stranded DNA breaks (DSBs). Although each of the shelterin proteins is important for telomere maintenance, Telomeric repeat-binding factor-2 (TRF2) has a particularly critical role. TRF2 regulates replicative senescence in part by reducing telomere length at senescence, ${ }^{8,9}$, and can also stop the ataxia telangiectasia kinase (ATM) from initiating a DDR from functional telomeres ${ }^{10}$. Loss of TRF2 induces multiple features of senescence, including irreversible growth arrest, expression of senescence-associated $\beta$ Galactosidase (SA $\beta G)$, and telomere dysfunction with chromosomal fusions ${ }^{11-13}$. TRF2 can also regulate cell longevity in a telomere-independent manner by direct association with multiple 
DDR proteins, including ATM, Nijmegen Breakage Syndrome-1 (NBS1), and Checkpoint kinase-2 (Chk2) ${ }^{14-16}$. ATM phosphorylates TRF2 after DNA damage on T188 in the dimerization domain ${ }^{17}$; defective phosphorylation (e.g. thr $>$ ala, T188A) prevents fast DNA repair following DSBs that is only part rescued by the phospho-mimetic glutamic acid (T188E) ${ }^{18}$. Despite differences in mouse and human telomeres, TRF2 inhibition can induce senescence and apoptosis in mouse tissues in vivo ${ }^{19}$.

We examined the expression of proteins that protect telomeres in human VSMCs derived from atherosclerotic plaques or normal arteries. We show that plaque VSMCs show reduced expression and telomere binding of TRF2, associated with increased markers of DNA damage. Gain and loss of function studies of TRF2 in $\mathrm{ApoE}^{-/-}$mice show that VSMC senescence regulates both plaque development and morphology. We conclude that plaque VSMC senescence in atherosclerosis is regulated by TRF2, and promotes both atherosclerosis and features of plaque vulnerability.

\section{Methods}

\section{Human atherosclerotic plaque and normal vessels}

Plaques and normal aorta were obtained from patients undergoing carotid endarterectomy or coronary artery bypass/valve replacement respectively, under informed consent using protocols approved by the Cambridge or Huntingdon Research Ethical Committee. Age and sex-matched human normal aorta and carotid plaque VSMCs were cultured from tissue explants and studied at passages 2-5; VSMC cultures from individual patients were not pooled. Cells were cultured in Dulbecco's modified Eagle's medium (DMEM) containing 20\% fetal calf serum (FCS) supplemented with $100 \mathrm{U} / \mathrm{ml}$ penicillin, $100 \mu \mathrm{g} / \mathrm{ml}$ streptomycin and $2 \mathrm{mM} \mathrm{L-glutamine.}$ 


\section{Protein Extraction, Western blotting}

Protein extraction from cultured cells and Western blotting were performed as previously described $^{20}$ and Supplemental Methods.

\section{ChIP}

TRF2 association with telomeres was examined by ChIP as described previously ${ }^{21}$ and Supplemental Methods.

\section{Immunocytochemistry}

Immunocytochemistry for nuclear foci was performed as described previously ${ }^{20}$ and Supplemental Methods.

\section{Immunohistochemistry}

Immunohistochemistry of human and mouse arteries was performed as described previously ${ }^{22}$.

\section{Plasmid Constructs}

cDNAs of human TRF2, TRF2 ${ }^{\triangle \mathrm{B}}$ (lacking N-terminal basic domain), TRF2 ${ }^{\triangle \mathrm{M}}$ (lacking C-

terminal Myb domain) and TRF2 $2^{\triangle \mathrm{B} \triangle \mathrm{M}}$ (lacking both basic and Myb domains) in retrovirus pWZL-hygro-nMyc vectors were purchased from Addgene, Ma, USA (originally supplied by Dr Titia de Lange, NY, USA). cDNAs from human TRF2 ${ }^{\text {T188A }}$ (constitutively un-phosphorylated at T188) and TRF2 ${ }^{\mathrm{T} 188 \mathrm{E}}$ (constitutively phosphorylated) in pTET vector were kind gifts from Dr. David Gilley (In, USA) and were subsequently subcloned into the pWZL-hygro-nMyc vector.

\section{Generation of Stable Cell Lines}

All cDNAs cloned into retrovirus pWZL-hygro-nMyc vectors (TRF2, TRF2 ${ }^{\triangle \mathrm{B}}, \mathrm{TRF}^{\Delta \mathrm{M}}{ }^{\text {, }}$ $\mathrm{TRF} 2^{\triangle \mathrm{B} \Delta \mathrm{M}}, \mathrm{TRF} 2^{\mathrm{T} 188 \mathrm{~A}}, \mathrm{TRF} 2^{\mathrm{T} 188 \mathrm{E}}$ ) or the empty vector were transfected into Bosc23 ecotropic packaging cells using HiPerfect transfection agent (Invitrogen). Replication-deficient virus was used to infect mouse ApoE ${ }^{-/}$VSMCs. Infected cells were selected with $250 \mu \mathrm{g} / \mathrm{ml}$ hygromycin 
(Roche) and TRF2 expression confirmed by western blot.

\section{Cell Culture}

Mouse cell lines were cultured as described in Supplemental Methods.

\section{Time Lapse Videomicroscopy}

Cells were cultured overnight in 6-well plates at $3 \times 10^{4}$ cells/well. Cells were incubated in $40 \mathrm{M}$ HEPES ( $\mathrm{pH}$ 7.2) for $1 \mathrm{~h}$ prior to recording using OpenLab software, taking 3 image frames/well using a time-lapse BX51 microscope (Olympus), air-cooled CCD camera (CoolSnap) and imaging and analysis software (Soft Imaging Systems). Over 100 cells per cell line were analysed and cell proliferation and apoptosis assayed. Non-division was defined as no observed divisions over 48 hours ( $\sim 4$ cycles).

SAßG

Detection of SA $\beta$ G was as previously described ${ }^{7}$. Comet Assay

$10^{5}$ cells were washed in PBS, re-suspended in $150 \mu 11 \%$ low melting point agarose (LMPA)/PBS and left to cool on Gelbond plastic films (Lonza) at $4^{\circ} \mathrm{C}$ for $10 \mathrm{~min}$. After immersing in lysis buffer (2.5M NaCl; $100 \mathrm{mM}$ EDTA; $10 \mathrm{mM}$ Trizma base; $\mathrm{pH} 10)$ overnight at $4^{\circ} \mathrm{C}$, gel-films were transferred into electrophoresis buffer $(0.3 \mathrm{M} \mathrm{NaOH} ; 1 \mathrm{mM}$ EDTA; $\mathrm{pH}>13)$ for $30 \mathrm{~min}$ prior to electrophoresis at $24 \mathrm{~V}, 300 \mathrm{~mA}$ for $30 \mathrm{~min}$ at $4^{\circ} \mathrm{C}$. Gel-films were washed 3 times in neutralization buffer ( $0.4 \mathrm{M}$ Tris, $\mathrm{pH} 7.5)$, once in distilled $\mathrm{H}_{2} \mathrm{O}$ and incubated in icecold ethanol for 10 min. Films were dried overnight, rehydrated in distilled $\mathrm{H}_{2} \mathrm{O}$ for 10 min and stained with $2 \mu \mathrm{g} / \mathrm{ml} \mathrm{EtBr}$ (Sigma) in the dark at room temperature for $2 \mathrm{~h}$. Multiple images per slide were analysed using a Zeiss microscope and comet tail length/moment measured using Comet Assay IV software (Perception Instruments). 


\section{Experimental Animals}

All animal procedures followed UK Home Office licensing and were approved by the local animal ethical committee. To produce constructs for transgenesis, HA tags were inserted at the N-terminus of TRF2 and TRF2 ${ }^{\mathrm{T} 188 \mathrm{~A}} \mathrm{cDNA}$ by enzymatic reaction. Tagged cDNAs were subcloned between the minimal SM22 $\alpha$ promoter ${ }^{23}$ and polyA sequence in a pBS vector. Transgenic mice expressing SM22 $\alpha$-TRF2 or -TRF2 ${ }^{\mathrm{T} 188 \mathrm{~A}}$ were generated by pro-nuclear injection. Founders were bred to ensure transgene transmission and expression, then backcrossed five times with $\mathrm{ApoE}^{-/}$mice prior to experiments. Male and female control $\mathrm{ApoE}^{-/-}, \mathrm{SM} 22 \alpha-$ TRF2/ApoE ${ }^{-/-}$or SM22 $\alpha-\mathrm{TRF}^{\mathrm{T} 188 \mathrm{~A}} / \mathrm{ApoE}^{-/-}$mice were fed a high fat diet (HFD- $21 \%$ total fat, $0.2 \%$ cholesterol, $0 \%$ sodium cholate) from $6 \mathrm{w}-22 \mathrm{w}$, and blood and tissues taken at sacrifice.

\section{Telomere length and TEL-FISH}

Telomere length and telomere fluorescence in situ hybridisation was undertaken on VSMCs derived from control and transgenic mice as described in Supplemental Methods.

\section{Plaque morphometry}

Atherosclerotic plaque morphometry was determined as described previously ${ }^{24}$ and in Supplemental methods.

\section{Lipid measurements, blood counts, blood pressure}

Blood was taken from experimental animals every 4 weeks, and serum lipids analysed for total cholesterol, triglycerides, LDL and HDL using a Dade-Behring Dimension autoanalyzer and LDL calculated using the Friedwald formula. Blood counts were analysed on a Coulter counter, and blood pressure determined by tail cuff.

\section{Cytokine and chemokine detection using FlowCytomix assay}

FlowCytomix assay (eBioscience) was used to determine chemokine (GM-CSF, MCP-1, MCP-3, 
MIP-1 $\alpha$, MIP-1 $\beta$, Rantes, CXCL1/KC) and cytokine (IL-6) concentrations in conditioned media from cell lines or mouse serum. Samples were analysed according to the manufacturer's recommendations.

\section{Statistical Analysis}

Data that were normally distributed (e.g. cultured cell foci and mouse plaque sizes) were compared using one-way ANOVA (GraphPad Prism, Ca, USA) with no adjustments for multiple comparisons. Data that were not normally distributed were examined using Mann Whitney U tests. Cumulative data (e.g. cumulative cell proliferation) were examined by comparison of cell divisions at the end of the experiment using Mann Whitney U tests. Data are expressed as Means \pm SEM or Means \pm SD. $p<0.05$ was considered statistically significant.

\section{Results}

TRF2 is reduced in human atherosclerotic plaque VSMCs

As human atherosclerotic plaque VSMCs show shortened telomeres and premature senescence ${ }^{7}$, we first examined expression of shelterin complex proteins in VSMCs cultured from normal human aorta or atherosclerotic plaques. Most proteins showed similar expression, but TRF2 was reduced in multiple plaque VSMC isolates (Figure 1A). Relative expression of each protein in plaque vs. aortic VSMCs was: TRF1 (0.88 $\pm 0.2, \mathrm{p}=0.43)$, TRF2 $(0.76 \pm 0.06, \mathrm{p}=0.011)$, POT1 $(0.68 \pm 0.3, \mathrm{p}=0.06)$, TIN2 $(1.06 \pm 0.1, \mathrm{p}=0.69), \mathrm{RAP} 1(1.03 \pm 0.1, \mathrm{p}=0.82)$, TPP1 $(0.88 \pm 0.13$, $\mathrm{p}=0.48)($ mean $\pm \mathrm{SD}, \mathrm{n}=3)$. In addition, ChIP showed that plaque VSMCs had markedly reduced TRF2 bound to telomeres by (Figure 1B), indicating that telomeres in plaque VSMCs are unprotected by TRF2.

TRF2 is regulated at both mRNA and protein levels. There was no difference in TRF2 
mRNA expression between aortic $(n=3)$ or plaque $(n=3)$ VSMCs (Figure 1C) by qPCR, despite the marked differences in TRF2 protein expression, suggesting post transcriptional regulation of TRF2 protein. In some cells the stability of TRF2 protein is regulated via ubiquitin-mediated proteasomal degradation, itself regulated by a p53-induced E3 ubiquitin ligase siah- $1 \mathrm{a}^{25}$. Consistent with previous studies ${ }^{26}$, p53 was increased in whole lysates of human plaques compared with normal vessels, and also increased in SMA-positive cells in plaques compared with normal aorta (Supplemental Figure 1). p53 itself is also regulated by proteasomal degradation, suggesting that this mechanism may be active. Indeed, although p53 protein expression was undetectable in plaque and normal human VSMCs by Western blot (not shown), expression of siah-1a was increased 1.9-fold in plaque vs. aortic VSMCs, associated with 3.5fold increased expression of the senescence marker p16 (n=3) (Figure 1D). To demonstrate whether p53 regulated TRF2 expression in VSMCs, we examined TRF2 levels in control or p531- VSMCs after treatment with the proteasomal inhibitor MG132. Proteasomal inhibition decreased TRF2 expression in control VSMCs (Figure 1E), associated with increased p53 expression. TRF2 was increased in $\mathrm{p} 53^{-/-}$null VSMCs, consistent with a role for $\mathrm{p} 53$ in regulating TRF2 protein expression, but there was no significant effect of MG132 (Figure 1E). We next examined whether reduced TRF2 expression in plaque VSMCs was associated with DNA damage. Cultured plaque VSMCs had reduced TRF2 nuclear foci, associated with increased foci of the DNA damage markers phosphorylated ATM (P-ATM) and $\gamma$-H2AX (Figure 2A-B). Despite reduced TRF2 foci, plaque VSMCs showed increased co-localization of TRF2 foci with P-ATM and $\gamma$-H2AX, indicating DNA damage at telomeres, and co-localization of $\gamma$-H2AX with P-ATM (Figure 2A-B). To confirm that TRF2 is also reduced in vivo, and its association with DNA damage markers, we examined cells in normal aorta or advanced plaque 
(AHA Grade IV+). Cells expressing $\gamma$-SMA in human plaques in vivo also showed reduced TRF2 and increased P-ATM and $\gamma$-H2AX expression (Figure 2C-D). These findings suggest that TRF2 expression and binding to telomeres is reduced in plaque VSMCs, associated with increased DNA damage and DDR activation at telomeres.

\section{TRF2 bypasses senescence whereas TRF2188A promotes VSMC senescence}

Reduced TRF2 in plaque VSMCs, and the known role of TRF2 in protecting against senescence, suggest that TRF2 may be a critical regulator of VSMC senescence. If correct, manipulation of TRF2 might be used to increase or decrease senescence in VSMCs in culture and in vivo to study the consequences of VSMC senescence on plaque development. TRF2 knockout is embryonally lethal in mice ${ }^{27}$. However, TRF2 contains different functional domains, including a C-terminal DNA-binding Myb domain that recognises telomeric tandem repeat sequences at chromosome ends, a flexible hinge domain involved in protein-protein interactions, a TRFH domain required for homodimerization, and a divergent $\mathrm{N}$-terminal domain rich in basic residues (basic domain). Deletion of these regions both alone and together can promote senescence in transformed cells or those from newborns, both mouse and human ${ }^{11,12}$, and thus act as a useful model for loss of TRF2 function. However, the effect of loss of TRF2 function varies widely between cell types (e.g. ${ }^{28}$ ), and the effect on VSMCs is not known, particularly VSMCs from atherosclerosis models such as $\mathrm{ApoE}^{-/-}$mice.

To find the most effective way of increasing or reducing TRF2 function in VSMCs, we stably expressed full-length human TRF2 or truncations lacking the basic domain ( $\triangle \mathrm{B})$, the Myb domain $(\Delta \mathrm{M})$, or both $(\Delta \mathrm{B} / \Delta \mathrm{M})$, or TRF2 $2^{\mathrm{T} 188 \mathrm{E} / \mathrm{A}}$ point mutations in mouse Apolipoprotein $\mathrm{E}^{-/-}$ VSMCs (Supplemental Figure 2A-B). Vector-expressing VSMCs senesced at $\sim$ passage 14; $\mathrm{TRF} 2, \mathrm{TRF}_{2}{ }^{\triangle \mathrm{B}}, \mathrm{TRF}^{\triangle \mathrm{M}}$ or TRF2 ${ }^{\triangle \mathrm{B} \Delta \mathrm{M}}$ all promoted cell proliferation (Supplemental Figure 
2C-D) and cells bypassed senescence until >passage 60 . In contrast, TRF2 ${ }^{\mathrm{T} 188 \mathrm{~A}}$ or TRF2 ${ }^{\mathrm{T} 188 \mathrm{E}}$ reduced cell proliferation and cells underwent premature senescence by passage 4 , associated with increased SA $\beta$ G expression (Supplemental Figure 2E), indicating that dynamic changes in TRF2 phosphorylation are particularly required for function in VSMCs. None of the TRF2 truncations/mutations significantly increased apoptosis (Supplemental Figure 2D).

\section{TRF2 promotes DNA repair, whereas TRF2188A delays repair}

We next examined DNA repair after t-BHP, an oxidant that promotes premature senescence in VSMCs in part through induction of DSBs and telomere damage ${ }^{7}$. As TRF2, TRF2 ${ }^{\Delta \mathrm{B}}, \mathrm{TRF}^{\triangle \mathrm{M}}$ and $\mathrm{TRF} 2^{\triangle \mathrm{B} \Delta \mathrm{M}}$ showed similar effects on cell proliferation and senescence, subsequent studies focused on TRF2 and TRF2 ${ }^{\text {T188A/E }}$. TRF2 was not detectable in control VSMCs, but t-BHP induced transient TRF2 phosphorylation in cells expressing ectopic TRF2, but not TRF2 ${ }^{\mathrm{T} 188 \mathrm{~A}}$ or TRF2 ${ }^{\mathrm{T} 188 \mathrm{E}}$, again consistent with the known role of this residue in TRF2 phosphorylation (Figure 3A). t-BHP increased $\gamma$-H2AX expression in control, TRF2 ${ }^{\mathrm{T} 188 \mathrm{~A}}$ and TRF2 ${ }^{\mathrm{T} 188 \mathrm{E}}$ VSMCs, but $\gamma-\mathrm{H} 2 \mathrm{AX}$ expression was markedly reduced in TRF2 VSMCs. $\gamma$-H2AX returned to baseline by $16 \mathrm{~h}$ in control and TRF2 ${ }^{\mathrm{T} 188 \mathrm{E}}$ cells, but TRF2 ${ }^{\mathrm{T} 188 \mathrm{~A}}$ VSMCs maintained $\gamma$-H2AX expression to 16h, indicating long-term unrepaired damage (Figure 3A). Thus, TRF2 inhibits DNA damage (as seen by the lack of $\gamma-\mathrm{H} 2 \mathrm{AX}$ expression at baseline and at any stage after DNA damage) and $\mathrm{TRF}^{\mathrm{T} 188 \mathrm{~A}}$ increases damage / inhibits repair (as seen by persistent $\gamma-\mathrm{H} 2 \mathrm{AX}$ at $16 \mathrm{~h}$ ). TRF2 overexpression also reduced both $\gamma$-H2AX and P-ATM foci $1 \mathrm{~h}$ after t-BHP (Figure 3B-D) and $\gamma$ $\mathrm{H} 2 \mathrm{AX}$ foci in recovery (Figure 3E); in contrast, TRF2 ${ }^{\mathrm{T} 188 \mathrm{~A}}$ increased $\gamma$-H2AX foci $1 \mathrm{~h}$ after tBHP (Figure 3C), which persisted to $>6 \mathrm{~h}$ in recovery (Figure 3E). TRF2 ${ }^{\mathrm{T} 188 \mathrm{E}}$ increased early $\gamma$ H2AX induction after t-BHP, but DNA damage normalized by 6h (Figure 3E).

DSBs can be quantified using an alkaline comet assay, with the kinetics of comet tail 
shortening reflecting efficiency of DSB repair. t-BHP-induced DSBs were repaired by $6 \mathrm{~h}$ in control VSMCs, but TRF2 accelerated repair with recovery by $2 \mathrm{~h}$; TRF-2 ${ }^{\mathrm{T} 188 \mathrm{E}}$ slowed initial DNA repair but was complete by $6 \mathrm{~h}$, whilst TRF2 ${ }^{\mathrm{T} 188 \mathrm{~A}}$ VSMCs showed markedly delayed repair to $>6 \mathrm{~h}$ (Figure 3F, Supplemental Figure 3). Thus, TRF2 overexpression inhibits replicative arrest in VSMCs, accelerates DSB repair after redox stress, and reduces DNA damage. $\mathrm{TRF} 2^{\mathrm{T} 188 \mathrm{~A} / \mathrm{E}}$ induce premature replicative arrest, delay DNA repair and increase DNA damage; these effects are most marked with TRF2 ${ }^{\mathrm{T} 188 \mathrm{~A}}$, and indicate that TRF2 and TRF2 ${ }^{\mathrm{T} 188 \mathrm{~A}}$ can be used to examine the effects of prevention or induction of VSMC senescence respectively. Generation and characterisation of VSMC-specific TRF2 or TRF2 ${ }^{188 A}$ transgenic mice To determine the role of VSMC senescence in atherogenesis and plaque stability, we generated transgenic mice that expressed TRF2 or TRF2 ${ }^{\mathrm{T} 188 \mathrm{~A}}$ from the minimal SM22 $\alpha$ promoter (Supplemental Figure 4). The minimal SM22 promoter is expressed only in arterial VSMCs in adult mice, and not in visceral SMCs, cardiomyocytes or skeletal myocytes ${ }^{23} \cdot 3$-bp mutations were also introduced into the promoter $\mathrm{CArG}(\mathrm{CC}(\mathrm{A} / \mathrm{T}) 6 \mathrm{GG}-)$ boxes to prevent promoter downregulation when VSMCs undergo phenotypic modulation ${ }^{29}$. Recent studies have shown that bone marrow-derived myeloid cells can express 'VSMC' markers in culture and atherosclerosis ${ }^{30}$, and vessel wall-derived VSMCs can also express 'macrophage' markers ${ }^{31}$. However, we have shown that this promoter is expressed in $<1 \%$ of myeloid cells that express 'VSMC' markers in atherosclerotic plaques in mice ${ }^{30}$, indicating that expression of transgenes from this promoter are specific for vessel-wall derived VSMCs.

Two founders from each line were studied, which each behaved similarly. SM22 $\alpha$-TRF2 and SM22 $\alpha-\mathrm{TRF}^{\mathrm{T} 188 \mathrm{~A}}$ mice were born with the expected frequencies, the transgene was transmitted between generations, and expressed only in arteries (Figure 4A). Although primary 
mouse VSMCs proliferate slower than mouse VSMC lines, VSMCs derived from SM22 $\alpha$-TRF2 mice showed the same features of increased proliferation (Figure 4B), reduced non-dividing \% (Figure 4C), and accelerated DSB repair (Figure 4D), particularly seen with normalization of Comet lengths by $2 \mathrm{~h}$ (Figure 4D). Similarly, SM22 $\alpha-\mathrm{TRF} 2^{\mathrm{T} 188 \mathrm{~A}}$ VSMCs showed decreased proliferation, increased non-dividing \%, and defective initial DSB repair, indicating that transgene expression in these mice recapitulates expression of TRF2 and TRF2 ${ }^{188 \mathrm{~A}}$ in $\mathrm{ApoE}^{-/-}$ VSMCs (Supplemental Figure 2). Importantly, apoptosis was similar in all cell types (Figure 4C), such that functional consequences of transgene expression in vivo were not due to increased/decrease VSMC apoptosis. SM22 $\alpha-$ TRF2 and SM22 $\alpha-$ TRF2 $^{\text {T188A }}$ mice showed no gross vascular or other abnormality, and $\gamma-\mathrm{H} 2 \mathrm{AX}$ expression was similar in aortas of all mouse groups, indicating that this overall DNA damage was not affected; in contrast, the senescence marker p16 was markedly increased in SM22 $\alpha-\mathrm{TRF}^{\mathrm{T} 188 \mathrm{~A}}$ mice (Figure 4E), confirming that TRF2 ${ }^{\text {T188A }}$ can induce markers of senescence in VSMCs in normal arteries in the absence of DNA damage.

The effect of TRF2 and TRF2 ${ }^{\mathrm{T} 188 \mathrm{~A}}$ on telomeres, telomere length and chromosome structure in VSMCs from transgenic mice was examined using qPCR for telomere length and telomere fluorescence in situ hybridisation. Although TRF2 reduced telomere length, this was not associated with telomere deletions, and there was a trend towards reduced telomere fusions, consistent with previous studies indicating a protective role for TRF2 overexpression ${ }^{8,32}$. In contrast, TRF $2^{\mathrm{T} 188 \mathrm{~A}}$ increased the incidence of telomere deletions, consistent with loss of telomere function (Supplemental Figure 5).

Effects of TRF2 or TRF2 ${ }^{188 \mathrm{~A}}$ on atherosclerosis

To examine the effect of VSMC senescence on atherosclerosis, SM22 $\alpha$-TRF2 and SM22 $\alpha-$ 
$\mathrm{TRF}^{\mathrm{T} 188 \mathrm{~A}}$ mice were backcrossed with C57B16/J ApoE ${ }^{-/}$mice, and male and female $\mathrm{ApoE}^{-/}$, $\mathrm{SM} 22 \alpha-\mathrm{TRF} 2 / \mathrm{ApoE}^{-/}$, or SM22 $\alpha-\mathrm{TRF}^{\mathrm{T}}{ }^{188 \mathrm{~A}} / \mathrm{ApoE}^{-/}$littermates were fat fed from $6 \mathrm{w}-22 \mathrm{w}$.

Body weight, blood pressure, serum lipids, total leukocyte counts, and differential leukocyte $\%$ showed no differences between groups (Supplemental Figure 6). However, both total atherosclerotic plaque and necrotic core areas were significantly increased in aortic root lesions of SM22 $\alpha-\mathrm{TRF}^{\mathrm{T} 188 \mathrm{~A}}$ mice (Figures 5 and 6, Table 1). Plaque area was also increased in brachiocephalic arteries of SM22 $\alpha-\mathrm{TRF} 2^{\mathrm{T} 188 \mathrm{~A}}$ mice $\left(0.60 \pm 0.08 \mathrm{~mm}^{2}\right)$ and reduced in SM22 $\alpha$ TRF2/ApoE $E^{-/-}$mice $\left(0.10 \pm 0.09 \mathrm{~mm}^{2}\right)$ compared to controls $\left(0.33 \pm 0.1 \mathrm{~mm}^{2}\right.$, Mean $\pm \mathrm{SEM}$ $\mathrm{p}=0.047$ ) (Supplemental Figure 7). Similar to human plaques, TRF2 was reduced in VSMCs in plaques of $\mathrm{ApoE}^{-/-}$mice vs. the undiseased media (Supplemental Figure 8).

In humans, rupture-prone plaques exhibit a thin fibrous cap and a relatively large necrotic core; we therefore undertook detailed analysis of plaque architecture in these mice. SM22 $\alpha$ TRF2 mice had significantly increased fibrous cap/plaque and cap/core ratios, and reduced core/plaque ratios compared with control $\mathrm{ApoE}^{-/-}$mice (Figure 6A-E, Table 1), indicating a relative increase in fibrous cap and decrease in core areas. Overall \% SMA-positive, mac3positive, and apoptosis frequencies were similar between groups (Table 1), although fibrous caps of SM22 $\alpha$-TRF2 mice showed more extensive SMA expression (Figure 5).

\section{Increased atherosclerosis in SM22 $\alpha$-TRF2 ${ }^{\mathrm{T} 188 \mathrm{~A}}$ mice is not due to a SASP}

Premature senescence may promote atherogenesis by reducing the VSMC content of fibrous caps, a major factor in promoting plaque rupture and subsequent growth in humans ${ }^{33}$. However, senescence can also induce a senescence-associated secretome (SASP), a pattern of proinflammatory cytokines released when cells (including VSMCs) undergo replicative or stressinduced premature senescence ${ }^{34}$ that might promote atherosclerosis by increasing monocyte 
invasion. However, both mac3-positive content of plaques (Table 1) and serum levels of SASP cytokines were similar (MCP-3, MCP-1, Mip-1 $\beta$, RANTES) or undetectable (Mip-1 $\alpha$, IL-1, IL6) in all mouse groups at 22w (Supplemental Figure 9).

To determine whether mouse VSMCs expressing TRF2 or TRF2 ${ }^{188 \mathrm{~A}}$ showed differences in SASP cytokine secretion, we cultured VSMCs expressing these proteins and determined cytokine secretion after 2 days. Conditioned media of $\mathrm{ApoE}^{-/}$VSMCs expressing TRF2 or $\mathrm{TRF}^{\mathrm{T} 188 \mathrm{~A}}$ showed similar cytokine secretion to control cells (Supplemental Figure 10). The increased atherosclerosis in SM22 $\alpha-\mathrm{TRF}^{\mathrm{T} 188 \mathrm{~A}}$ mice with a similar SASP profile in vivo and in culture thus suggests that VSMCs exert a direct protective effect on the vessel wall.

\section{Discussion}

VSMC proliferation is a fundamental component of both historical and current models of atherogenesis. For example, the 'response to injury' hypothesis viewed aberrant VSMC proliferation as a major primary event in plaque development. In contrast, more recent models suggest that VSMC proliferation is predominantly reparative, for example as a response to inflammation ${ }^{35,36}$. While increased VSMC proliferation is seen in atherogenesis, VSMCs in advanced human plaques are characterised by multiple markers of senescence, including telomere loss, expression of the cyclin-dependent kinase inhibitors p21 and p16, and expression of $\mathrm{SA} \beta \mathrm{G}^{7}$. Although this indicates that VSMC senescence occurs in advanced plaques, it is not known whether senescence contributes to plaque development or the morphology of advanced lesions, or its underlying mechanisms.

We demonstrate that human atherosclerotic plaque VSMCs show reduced TRF2 expression in vitro and markedly reduced binding of TRF2 to telomeres, associated with 
increased markers of DNA damage. Other shelterin proteins showed no consistently altered expression, suggesting that TRF2 is a critical regulator of VSMC senescence in atherosclerosis, and that plaque VSMCs are very sensitive to telomere damage. TRF2 was also reduced and associated markers of DNA damage increased in $\alpha$-SMA-positive cells in human plaques in vivo. TRF2 protein was regulated by proteasomal degradation that depended upon p53. TRF2 reduced DNA damage, accelerated DSB repair, and inhibited replicative arrest in VSMCs, indicating that VSMC senescence may be due to both replicative exhaustion and stress-induced premature senescence (SIPS). Using novel gain and loss of function VSMC-specific expression of TRF2 or TRF2 ${ }^{\mathrm{T} 188 \mathrm{~A}}$, we show that VSMC senescence promotes atherosclerosis and features of plaque vulnerability, including decreased relative fibrous cap and increased necrotic core areas, without a significant SASP.

We show that TRF2 is unique of the shelterin proteins in being downregulated in plaque VSMCs. TRF2 protein is regulated by ubiquitin-mediated degradation, in part by the p53induced E3 ubiquitin ligase siah $1^{25}$. VSMCs in plaques are characterised by multiple forms of DNA damage, including double and single strand breaks, oxidative lesions and mtDNA damage $^{37,38}$, and DNA damage markers and activation of multiple DNA repair pathways are maintained in cultured plaque VSMCs ${ }^{7,20,38}$. Plaque VSMCs in culture and cells expressing $\alpha$ SMA in human plaques showed down-regulated TRF2 associated with markers of both DNA damage $(\gamma-\mathrm{H} 2 \mathrm{AX})$ and DNA repair (p-ATM). In culture, plaque VSMCs showed reduced TRF2 and increased siah-1a, associated with increased p16. Although overall TRF2 expression was reduced after proteasomal inhibition, this was also associated with marked upregulation of $\mathrm{p} 53$, and the effect of proteasomal inhibition on TRF2 expression was dependent upon p53. This suggests a specific mechanism for TRF2 down-regulation in atherosclerosis by which DNA 
damage-induced activation of p53 and subsequently siah-1a results in TRF2 degradation in plaque VSMCs.

Although studies on human plaque VSMCs do not indicate if reduced TRF2 is a cause or consequence of senescence, we show that overexpression of TRF2 from a retrovirus promoter or from transgenic mice using the SM22 $\alpha$ minimal promoter blocks cell senescence in culture. The latter is not a strong promoter, indicating that endogenous levels of TRF2 may be sufficient to prevent senescence. This hypothesis is strengthened by our studies using TRF2 ${ }^{188 \mathrm{~A}}$ which induces senescence in VSMCs that express endogenous levels of wild type TRF2. The use of both gain and loss of function studies in vitro that show opposite effects strongly imply that TRF2 is a critical regulator of VSMC senescence, and that the observed loss of TRF2 is a major factor in VSMC senescence in atherosclerosis.

To determine the effects of manipulating TRF2 in VSMCs in vivo on atherogenesis and plaque morphology directly we generated two novel transgenic mouse models that express VSMC-specific TRF2 or TRF2 ${ }^{188 \mathrm{~A}}$ as gain or loss of function respectively. TRF2 and TRF2 ${ }^{188 \mathrm{~A}}$ were expressed at similar levels, a critical control to be able to compare their effects. TRF2 promoted proliferation, inhibited senescence, and accelerated DNA repair in VSMCs derived from SM22 $\alpha$-TRF2 mice, whereas TRF2 ${ }^{188 \mathrm{~A}}$ did the opposite. Furthermore, in normal aortas $\mathrm{TRF}^{188 \mathrm{~A}}$ increased $\mathrm{p} 16$ expression with no change in $\gamma-\mathrm{H} 2 \mathrm{AX}$, indicating that TRF2 ${ }^{188 \mathrm{~A}}$ can promote VSMC senescence in the absence of widespread DNA damage. TRF2 ${ }^{188 \mathrm{~A}}$ promoted plaque development associated with increased plaque and necrotic core areas, whereas TRF2 expression increased the fibrous cap area relative to both plaque and core areas, and reduced relative core size, with no change in apoptosis in either mouse group.

Recent genetic lineage tracing studies indicate that conventional markers of macrophages 
can also be expressed by cells derived from the vessel wall ${ }^{31}$, and markers of VSMCs can also be expressed by myeloid cells that differentiate in culture or migrate into the plaque ${ }^{30}$. This potentially might mean that myeloid cells activate 'VSMC' promoters when they migrate into atherosclerotic plaques, confounding our interpretation that the effects we observe are due to the effects of loss of TRF2 on vessel-wall derived VSMCs. However, we and others have shown that bone marrow-derived cells expressing SMC markers are either infrequent ${ }^{30}$ or non-existent $^{39}$ in plaques in ApoE mice, and could not be demonstrated in fibrous caps of advanced plaques at $22 \mathrm{w}^{30}$. We have also transplanted bone marrow-derived cells into $\mathrm{ApoE}^{-/-}$mice with transgenes expressed from the minimal SM22 $\alpha$ promoter, which showed that $<1 \%$ of cells in advanced plaques expressed the transgene, and again there was no expression in fibrous caps ${ }^{30}$. Thus, the opposite effects of TRF2 and TRF2 ${ }^{188 \mathrm{~A}}$ expression on plaque morphology argue strongly that changes in TRF2 function in these transgenic mice are mediated through senescence of vessel wall-derived VSMCs.

Premature senescence may promote atherogenesis by reducing the protective fibrous cap (as demonstrated here), or via a senescence-associated secretome (SASP), that might promote atherosclerosis by increasing monocyte invasion, or both. However, it has been difficult to demonstrate a functionally important SASP in mouse cells, and this often requires culture in physiological oxygen concentrations and extreme measures such irradiation ${ }^{40}$. In addition, senescence induced by p16 (which is increased in SM22 $\alpha-$ TRF2 $^{\mathrm{T} 188 \mathrm{~A}}$ VSMCs and human plaque VSMCs) is often not associated with a SASP ${ }^{41}$. We find no differences in 'classical' SASP cytokines in serum of transgenic mice compared with controls, or in cultured VSMCs expressing TRF2 of TRF2 ${ }^{188 A}$. While it is possible that a local SASP may influence cellular composition and morphology of plaques in vivo, other anti-atherogenic effects of VSMCs should also be 
considered, including acting as a barrier to invasion of monocytes, or prevention of plaque rupture that leads to plaque growth. In particular, our findings illustrate the profound protective properties of normal VSMC function on the vessel wall, and a novel role of VSMC senescence in necrotic core formation. Our results may also explain why accelerated atherosclerosis and myocardial infarction are features of progeroid syndromes that show loss of VSMCs, DNA damage, and premature cellular senescence ${ }^{42}$, and why genes that regulate senescence such as the INK4/ARF locus might be associated with heart attacks in GWAS studies ${ }^{43}$.

Our data support a model of VSMC senescence in atherosclerosis involving telomere dysfunction, DNA damage, TRF2 and p53 (Figure 7). In atherogenesis, mitogens from platelets, invading myeloid cells, and the local vessel wall promote VSMC replication. Inflammation and reactive oxygen species (for example) promote DNA damage, including in telomeres of replicating cells. DNA damage also activates p53, resulting in siah1-mediated degradation of TRF2, which causes exposure of telomere ends. The combination of replication, loss of TRF2 protection, and direct DNA damage induce telomere dysfunction. Telomere dysfunction results in activation of a DNA damage response that further activates p53, and induction of $\mathrm{p} 16$. The p53 target p21 and p16 induce senescence, in part mediated through hypophosphorylation of pRB.

In summary, we show that TRF2 is a major regulator of VSMC senescence, and is downregulated in VSMCs from human atherosclerotic plaques. VSMC senescence promotes atherogenesis and necrotic core formation, while reducing cap formation. Protection against VSMC senescence may represent a novel mechanism to reduce both plaque formation and features of vulnerable plaques. 
Acknowledgments: We thank members of the Molecular Cytogenetics Unit, Welcome Trust Sanger Institute, UK) for technical assistance with TEL-FISH.

Funding Sources: This work was supported by British Heart Foundation grants RG/08/009/25841, PG/11/112/29272, and PG/09/071, the NIHR Cambridge Biomedical Research Centre, the Cambridge BHF Centre for Research Excellence, and the Oxbridge Centre for Regenerative Medicine.

\section{Conflict of Interest Disclosures: None.}

\section{References:}

1. Ross R, Glomset JA. Atherosclerosis and the arterial smooth muscle cell. Proliferation of smooth muscle is a key event in the genesis of the lesions of atherosclerosis. Science. 1973;180:1332-1339.

2. Libby P. Inflammation in atherosclerosis. Nature. 2002;420:868-874.

3. Davies MJ. Acute coronary-thrombosis - the role of plaque disruption and its initiation and prevention. Eur Heart J. 1995;16:3-7.

4. Virmani R, Burke AP, Farb A. Plaque rupture and plaque erosion. Thromb Haemost. 1999;82 Suppl 1:1-3.

5. Bennett M, Evan G, Schwartz S. Apoptosis of human vascular smooth muscle cells derived from normal vessels and coronary atherosclerotic plaques. J Clin. Invest. 1995;95:2266-2274.

6. O'Brien ER, Alpers CE, Stewart DK, Ferguson M, Tran N, Gordon D, Benditt EP, Hinohara T, Simpson JB, Schwartz SM. Proliferation in primary and restenotic coronary atherectomy tissue. Implications for antiproliferative therapy. Circ Res. 1993;73:223-231.

7. Matthews C, Gorenne I, Scott S, Figg N, Kirkpatrick P, Ritchie A, Goddard M, Bennett M. Vascular smooth muscle cells undergo telomere-based senescence in human atherosclerosis: Effects of telomerase and oxidative stress. Circ Res. 2006;99:156-164.

8. Karlseder J, Smogorzewska A, de Lange T. Senescence induced by altered telomere state, not telomere loss. Science. 2002;295:2446-2449.

9. Richter T, Saretzki G, Nelson G, Melcher M, Olijslagers S, von Zglinicki T. TRF2 overexpression diminishes repair of telomeric single-strand breaks and accelerates telomere shortening in human fibroblasts. Mech Ageing Dev. 2007;128:340-345. 
10. Denchi EL, de Lange T. Protection of telomeres through independent control of ATM and ATR by TRF2 and POT1. Nature. 2007;448:1068-1071.

11. van Steensel B, Smogorzewska A, de Lange T. TRF2 protects human telomeres from end-toend fusions. Cell. 1998;92:401-413.

12. Karlseder J, Broccoli D, Dai Y, Hardy S, de Lange T. p53- and ATM-dependent apoptosis induced by telomeres lacking TRF2. Science. 1999;283:1321-1325.

13. Smogorzewska A, de Lange T. Different telomere damage signaling pathways in human and mouse cells. EMBO J. 2002;21:4338-4348.

14. Karlseder J, Hoke K, Mirzoeva OK, Bakkenist C, Kastan MB, Petrini JH, de Lange T. The telomeric protein TRF2 binds the ATM kinase and can inhibit the ATM-dependent DNA damage response. PLoS Biol. 2004;2:E240.

15. Zhu XD, Kuster B, Mann M, Petrini JH, de Lange T. Cell-cycle-regulated association of RAD50/MRE11/NBS1 with TRF2 and human telomeres. Nat Genet. 2000;25:347-352.

16. Buscemi G, Zannini L, Fontanella E, Lecis D, Lisanti S, Delia D. The shelterin protein TRF2 inhibits CHK2 activity at telomeres in the absence of DNA damage. Curr Biol. 2009;19:874-879.

17. Tanaka H, Mendonca MS, Bradshaw PS, Hoelz DJ, Malkas LH, Meyn MS, Gilley D. DNA damage-induced phosphorylation of the human telomere-associated protein TRF2. Proc Natl Acad Sci USA. 2005;102:15539-15544.

18. Huda N, Tanaka H, Mendonca MS, Gilley D. DNA damage-induced phosphorylation of TRF2 is required for the fast pathway of DNA double-strand break repair. Mol Cell Biol. 2009;29:3597-3604.

19. Lechel A, Satyanarayana A, Ju Z, Plentz RR, Schaetzlein S, Rudolph C, Wilkens L, Wiemann SU, Saretzki G, Malek NP, Manns MP, Buer J, Rudolph KL. The cellular level of telomere dysfunction determines induction of senescence or apoptosis in vivo. EMBO Rep. 2005;6:275-281.

20. Mahmoudi M, Gorenne I, Mercer J, Figg N, Littlewood T, Bennett M. Statins use a novel nijmegen breakage syndrome-1-dependent pathway to accelerate DNA repair in vascular smooth muscle cells. Circ Res. 2008;103:717-725.

21. Hewitt G, Jurk D, Marques FD, Correia-Melo C, Hardy T, Gackowska A, Anderson R, Taschuk M, Mann J, Passos JF. Telomeres are favoured targets of a persistent DNA damage response in ageing and stress-induced senescence. Nat Commun. 2012;3:708.

22. Mercer J, Figg N, Stoneman V, Braganza D, Bennett MR. Endogenous p53 protects vascular smooth muscle cells from apoptosis and reduces atherosclerosis in ApoE knockout mice. Circ Res. 2005;96:667-674. 
23. Li L, Miano JM, Mercer B, Olson EN. Expression of the SM22alpha promoter in transgenic mice provides evidence for distinct transcriptional regulatory programs in vascular and visceral smooth muscle cells. J Cell Biol. 1996;132:849-859.

24. Clarke MC, Figg N, Maguire JJ, Davenport AP, Goddard M, Littlewood TD, Bennett MR. Apoptosis of vascular smooth muscle cells induces features of plaque vulnerability in atherosclerosis. Nat Med. 2006;12:1075-1080.

25. Fujita K, Horikawa I, Mondal AM, Jenkins LM, Appella E, Vojtesek B, Bourdon JC, Lane DP, Harris CC. Positive feedback between p53 and TRF2 during telomere-damage signalling and cellular senescence. Nat Cell Biol. 2010;12:1205-1212.

26. Martinet W, Knaapen MW, De Meyer GR, Herman AG, Kockx MM. Elevated levels of oxidative DNA damage and DNA repair enzymes in human atherosclerotic plaques. Circulation. 2002;106:927-932.

27. Celli GB, de Lange T. DNA processing is not required for ATM-mediated telomere damage response after TRF2 deletion. Nat Cell Biol. 2005;7:712-718.

28. Lazzerini Denchi E, Celli G, de Lange T. Hepatocytes with extensive telomere deprotection and fusion remain viable and regenerate liver mass through endoreduplication. Genes Dev. 2006;20:2648-2653.

29. Hendrix JA, Wamhoff BR, McDonald OG, Sinha S, Yoshida T, Owens GK. 5' CArG degeneracy in smooth muscle alpha-actin is required for injury-induced gene suppression in vivo. J Clin Invest. 2005;115:418-427.

30. Yu H, Stoneman V, Clarke M, Figg N, Xin HB, Kotlikoff M, Littlewood T, Bennett M. Bone marrow-derived smooth muscle-like cells are infrequent in advanced primary atherosclerotic plaques but promote atherosclerosis. Arterioscler Thromb Vasc Biol. 2011;31:1291-1299.

31. Feil S, Fehrenbacher B, Lukowski R, Essmann F, Schulze-Osthoff K, Schaller M, Feil R. Transdifferentiation of vascular smooth muscle cells to macrophage-like cells during atherogenesis. Circ Res. 2014;115:662-667.

32. Smogorzewska A, van Steensel B, Bianchi A, Oelmann S, Schaefer MR, Schnapp G, de Lange T. Control of human telomere length by TRF1 and TRF2. Mol Cell Biol. 2000;20:16591668.

33. Burke AP, Kolodgie FD, Farb A, Weber DK, Malcom GT, Smialek J, Virmani R. Healed plaque ruptures and sudden coronary death: Evidence that subclinical rupture has a role in plaque progression. Circulation. 2001;103:934-940.

34. Wang JC, Bennett M. Aging and atherosclerosis: Mechanisms, functional consequences, and potential therapeutics for cellular senescence. Circ Res. 2012;111:245-259. 
35. Glass CK, Witztum JL. Atherosclerosis. The road ahead. Cell. 2001;104:503-516.

36. Libby P, Ridker PM, Maseri A. Inflammation and atherosclerosis. Circulation. 2002;105:1135-1143.

37. Yu E, Calvert PA, Mercer JR, Harrison J, Baker L, Figg NL, Kumar S, Wang JC, Hurst LA, Obaid DR, Logan A, West NE, Clarke MC, Vidal-Puig A, Murphy MP, Bennett MR. Mitochondrial DNA damage can promote atherosclerosis independently of reactive oxygen species through effects on smooth muscle cells and monocytes and correlates with higher-risk plaques in humans. Circulation. 2013;128:702-712.

38. Gray K, Kumar S, Figg N, Harrison J, Baker L, Mercer J, Littlewood T, Bennett M. Effects of DNA damage in smooth muscle cells in atherosclerosis. Circ Res. 2015;116:816-826.

39. Bentzon JF, Weile C, Sondergaard CS, Hindkjaer J, Kassem M, Falk E. Smooth muscle cells in atherosclerosis originate from the local vessel wall and not circulating progenitor cells in ApoE knockout mice. Arterioscler Thromb Vasc Biol. 2006;26:2696-2702.

40. Coppe JP, Patil CK, Rodier F, Krtolica A, Beausejour CM, Parrinello S, Hodgson JG, Chin $\mathrm{K}$, Desprez PY, Campisi J. A human-like senescence-associated secretory phenotype is conserved in mouse cells dependent on physiological oxygen. PLoS One. 2010;5:e9188.

41. Coppe JP, Rodier F, Patil CK, Freund A, Desprez PY, Campisi J. Tumor suppressor and aging biomarker p16(ink4a) induces cellular senescence without the associated inflammatory secretory phenotype. J Biol Chem. 2011;286:36396-36403.

42. Minamino T, Komuro I. Vascular aging: Insights from studies on cellular senescence, stem cell aging, and progeroid syndromes. Nat Clin Pract Cardiovasc Med. 2008;5:637-648.

43. Jeck WR, Siebold AP, Sharpless NE. Review: A meta-analysis of GWAS and age-associated diseases. Aging Cell.11:727-731. 
Table 1. Morphometric and immunohistochemical quantification of aortic root atherosclerotic plaques in Control ApoE ${ }^{-/}$, SM22 $\alpha-\mathrm{TRF} 2 / \mathrm{ApoE}^{-/-}$, and SM22 $\alpha-\mathrm{TRF}^{\mathrm{T} 188 \mathrm{~A}} / \mathrm{ApoE}^{-/-}$mice at $22 \mathrm{w}$ after fat feeding from 6-22w. Data are means $\pm \mathrm{SD}$. ${ }^{*} \mathrm{p}<0.05 \mathrm{vs}$. control $\mathrm{ApoE}^{-/}$mice.

\begin{tabular}{|c|c|c|c|c|}
\hline & $\begin{array}{c}\text { Control }\left(\mathrm{ApoE}^{-/-}\right) \\
(\mathbf{n}=\mathbf{1 8})\end{array}$ & $\begin{array}{c}\text { SM22 } \alpha- \\
\text { TRF2/ApoE } \\
\quad(\mathbf{n}=11)\end{array}$ & $\begin{array}{c}\text { SM22 }^{12-} \\
\text { TRF2T }^{188 A} / \text { ApoE }^{-/-} \\
(n=11)\end{array}$ & $\begin{array}{c}\text { p Value } \\
\text { (ANOVA) }\end{array}$ \\
\hline $\begin{array}{l}\text { Plaque area } \\
\left(\mu \mathrm{m}^{2}\right)\end{array}$ & $386764 \pm 159285$ & $381339 \pm 141513$ & $531202 \pm 196287^{*}$ & 0.044 \\
\hline $\begin{array}{l}\text { Necrotic core } \\
\text { area }\left(\mu \mathrm{m}^{2}\right)\end{array}$ & $266685 \pm 140666$ & $217660 \pm 110186$ & $377240 \pm 177253 *$ & 0.046 \\
\hline Cap area $\left(\mu \mathrm{m}^{2}\right)$ & $123466 \pm 43778$ & $163679 \pm 60618$ & $159371 \pm 43281$ & 0.08 \\
\hline Cap/Plaque ratio & $0.33 \pm 0.099$ & $0.45 \pm 0.103^{*}$ & $0.33 \pm 0.107$ & 0.013 \\
\hline Cap/Core ratio & $0.50 \pm 0.211$ & $0.87 \pm 0.302 *$ & $0.53 \pm 0.276$ & 0.003 \\
\hline Core/Plaque ratio & $0.67 \pm 0.099$ & $0.55 \pm 0.107^{*}$ & $0.67 \pm 0.107$ & 0.013 \\
\hline SMA (\% area) & $14.17 \pm 6.60$ & $14.26 \pm 6.27$ & $12.90 \pm 5.18$ & 0.85 \\
\hline Mac3 (\% area) & $15.94 \pm 8.84$ & $14.36 \pm 5.98$ & $17.20 \pm 6.80$ & 0.70 \\
\hline TUNEL (\% cells) & $0.061 \pm 0.11$ & $0.209 \pm 0.26$ & $0.129 \pm 0.195$ & 0.16 \\
\hline
\end{tabular}

Figure Legends:

Figure 1. Human Plaque VSMCs show reduced TRF2 expression. (A) Western blot of shelterin proteins from normal human aortic $(n=3)$ or plaque VSMCs $(n=3)$. (B) Immunoprecipitation of TRF2 with telomere sequences in aorta (Ao) or plaque (P1) VSMCs (n=3). (C) qPCR for TRF2 in normal aortic $(n=3)$ or plaque VSMCs. Data are Means \pm SEM, $n=3$. (D) Western blot of plaque and normal VSMCS for siah1a and p16 $(\mathrm{n}=3)$. (E) Western blot of control or p53/- null mouse VSMCs after treatment with $10 \mu \mathrm{M}$ MG132 for 5 hours ( $\mathrm{n}=2)$.

Figure 2. Human Plaque VSMCs show reduced TRF2 and increased DNA damage. (A) Nuclear foci of TRF2, $\gamma$-H2AX or P-ATM in aortic or plaque VSMCs. (B) Quantification of single or 
combined foci ( $\mathrm{n}=20)$. (C-D) Immunohistochemistry for $\alpha$-sm-actin (SMA-blue) and either TRF2, $\gamma$-H2AX or P-ATM (brown) in normal aorta or plaque. Double-labeled panels are from areas indicated in $\mathrm{H}+\mathrm{E}$ in aortic media and fibrous cap. Scale bars $=50 \mu \mathrm{m}$. Insets are high power views of outlined areas. Data are means \pm SEM, $\mathrm{n}=5$.

Figure 3. TRF2 inhibits and TRF2 ${ }^{\text {T188A }}$ increases DNA damage. (A) Western blot for TRF2 and

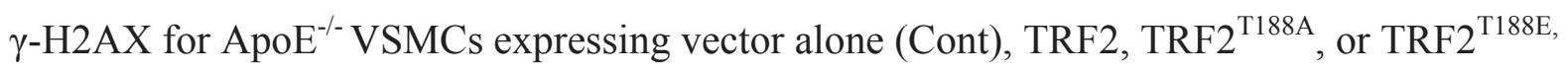
after treatment with $100 \mu \mathrm{M}$ t-BHP for 1 hour and recovery (Rec.) for either 2 (upper panels) or 16 hours (lower panels). (B) Immunocytochemistry of VSMCs from (A) 1h after t-BHP showing nuclear foci of TRF2/ $\gamma$-H2AX, or TRF2/P-ATM. (C,D) Quantification of nuclear foci in (B) $1 \mathrm{~h}$ after t-BHP. (E,F) $\gamma$-H2AX foci $(\mathbf{E})$ or comet tail moment $(\mathbf{F})$ in VSMCs 1 h after t-BHP (time 0) and 1,2 or 6 hours recovery. Data are means \pm SEM. $n=3 .{ }^{*} p<0.05,{ }^{* *} p<0.01$ vs. controls.

Figure 4. VSMCs from TRF2 and TRF2 ${ }^{\mathrm{T} 188 \mathrm{~A}}$ transgenic mice show increased or decreased proliferation and DNA repair respectively. (A) qPCR for SM22 $\alpha$-TRF2/TRF2 ${ }^{\mathrm{T} 188 \mathrm{~A}}$ transgene mRNA in two SM22 $\alpha$-TRF2 or SM22 $\alpha-$ TRF$^{\text {T188A }}$ founders (aorta), or gut. (B-D) Basal cell proliferation (B) or \% cell populations (C), or Comet tail moment after 1h of $100 \mu \mathrm{M} \mathrm{t}-\mathrm{BHP}$ and 5h recovery (D) in VSMCs from control or transgenic mice. (E) Western blot for TRF2, $\gamma$-H2AX and p16 in aortas of control ApoE ${ }^{-/}$(Control), SM22 $\alpha-$ TRF$_{2} / \mathrm{ApoE}^{-/}$(TRF2) or SM22 $\alpha-$ $\mathrm{TRF}^{\mathrm{T} 188 \mathrm{~A}} / \mathrm{ApoE}^{-/-}\left(\mathrm{TRF}^{\mathrm{T} 188 \mathrm{~A}}\right)$ at $22 \mathrm{w}$. Data are means $\pm \mathrm{SEM} \mathrm{n}=3 .{ }^{*} \mathrm{p}<0.05$ vs. controls.

Figure 5. Effects of TRF2 on plaque development and morphology. Histochemistry and immunohistochemistry of control, SM22 $\alpha$-TRF2 or SM22 $\alpha-T R F 2^{\text {T188A }}$ mouse aortic roots for 
Masson's Trichrome, $\alpha$-SMA and Mac3 at 22w after fat feeding from 6-22w. High power views represent areas outlined on corresponding low power views above. Scale bar=500 $\mathrm{m}$ (low power), and $150 \mu \mathrm{m}$ (high power).

Figure 6. Morphometry of plaques in experimental mice. (A-E) Quantification of aortic root plaque, core and cap areas and ratios in Control $\mathrm{ApoE}^{-/-}$, SM22 $\alpha-\mathrm{TRF}_{2} / \mathrm{ApoE}^{-/}$, and SM22 $\alpha-$ $\mathrm{TRF}^{\mathrm{T} 188 \mathrm{~A}} / \mathrm{ApoE}^{-/-}$mice at $22 \mathrm{w}$ after fat feeding from 6-22w. Data are means \pm SEM. $\mathrm{n}=11-18$.

Figure 7. Model of VSMC senescence in atherosclerosis. A full description is given in the text. 
A

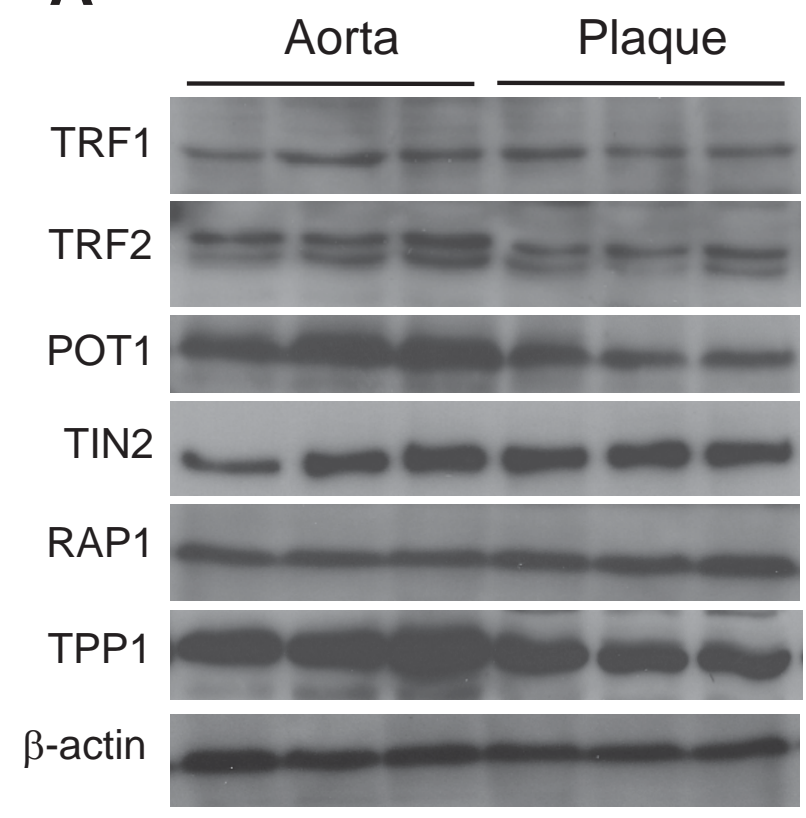

\section{B}
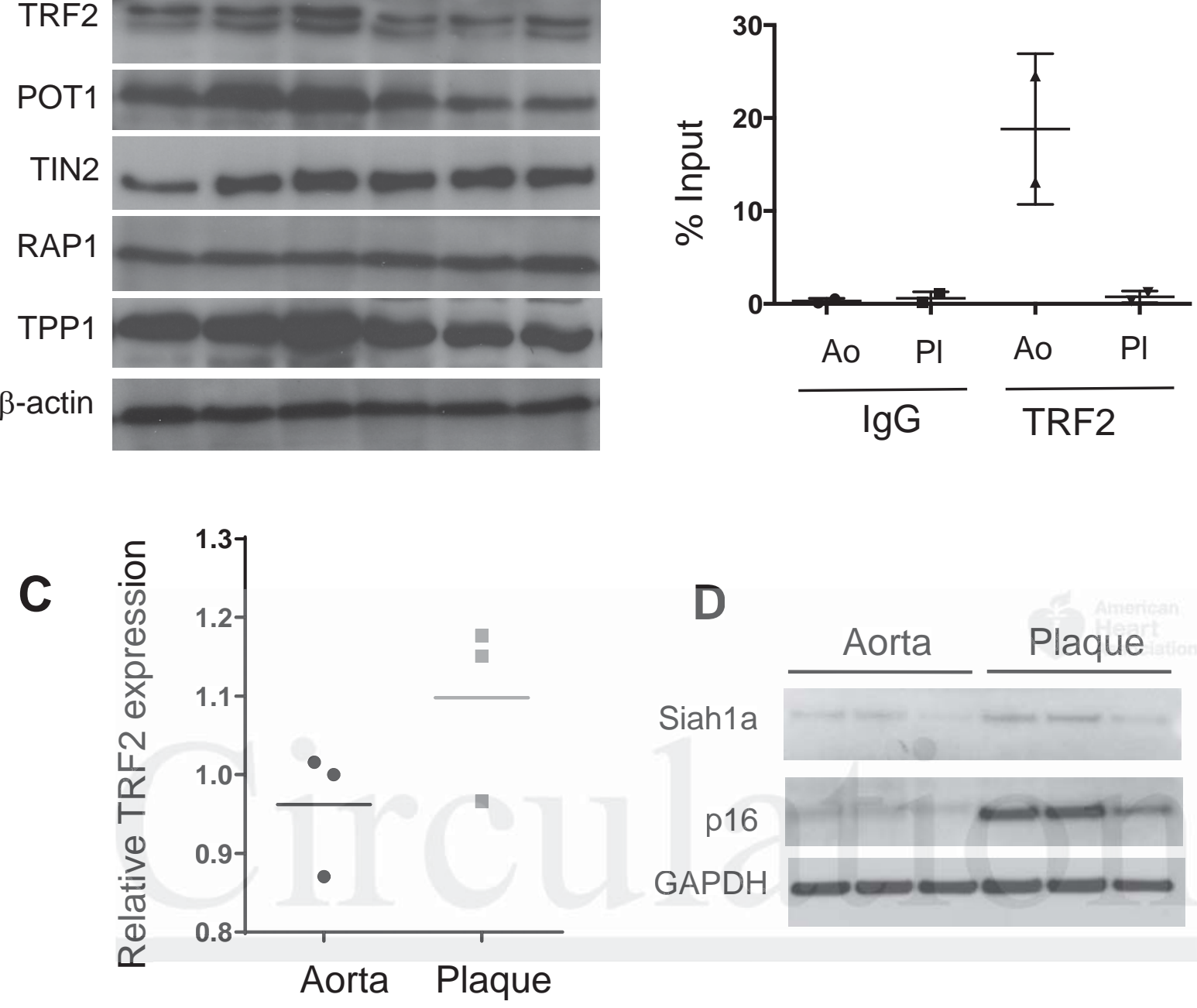

D

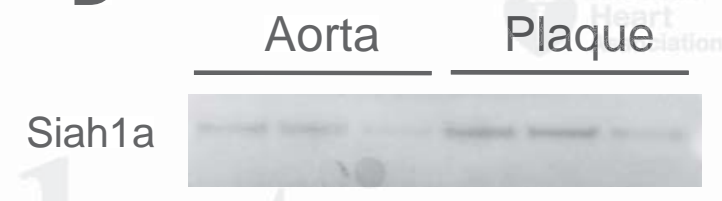

p16

GAPDH

E

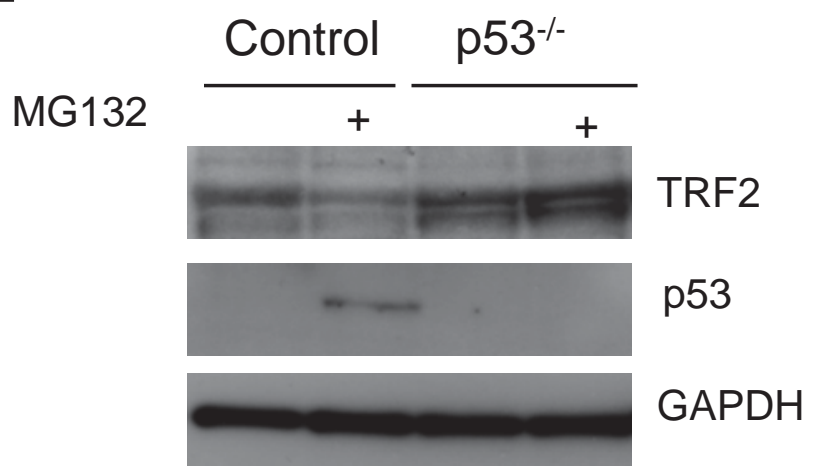

Figure 1 
A

Aorta

Plaque

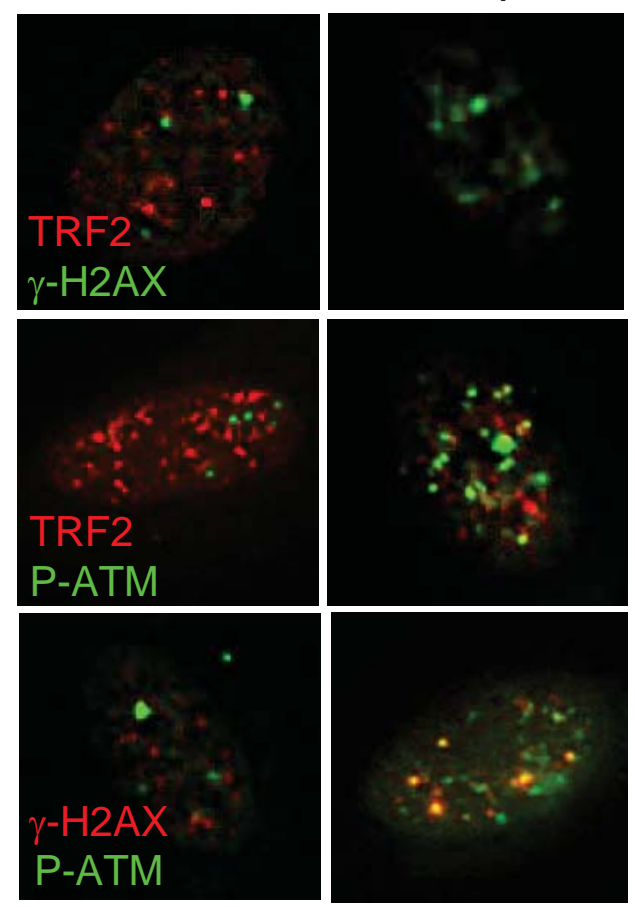

B $p=0.0001$

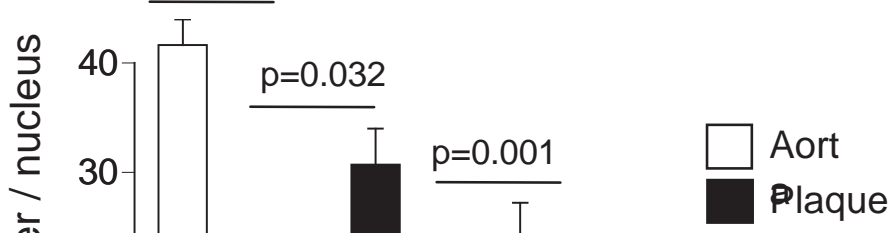

C

Aorta

Plaque

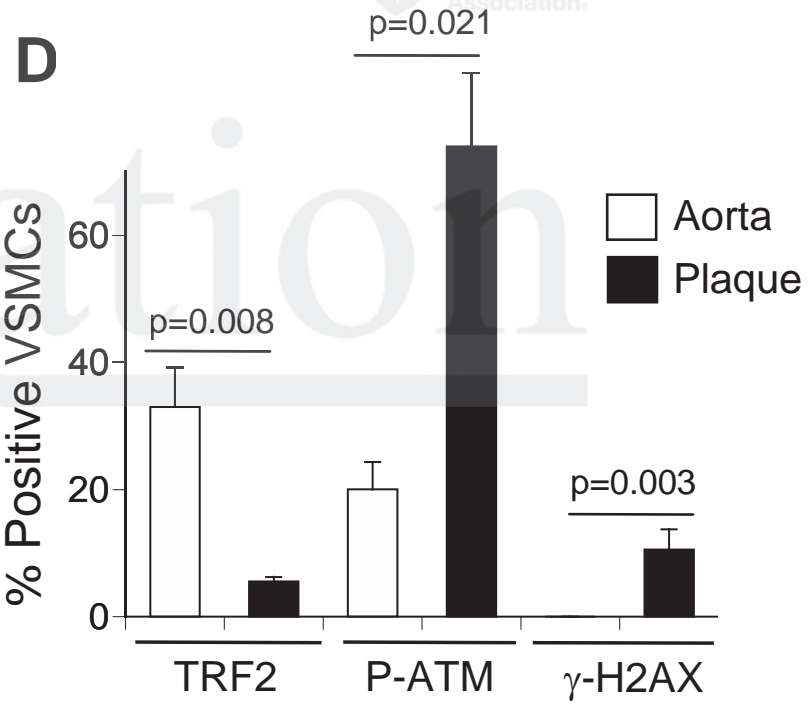

SMA

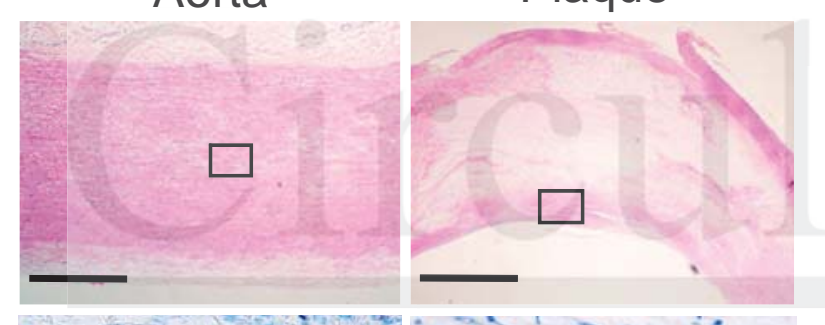

SMA
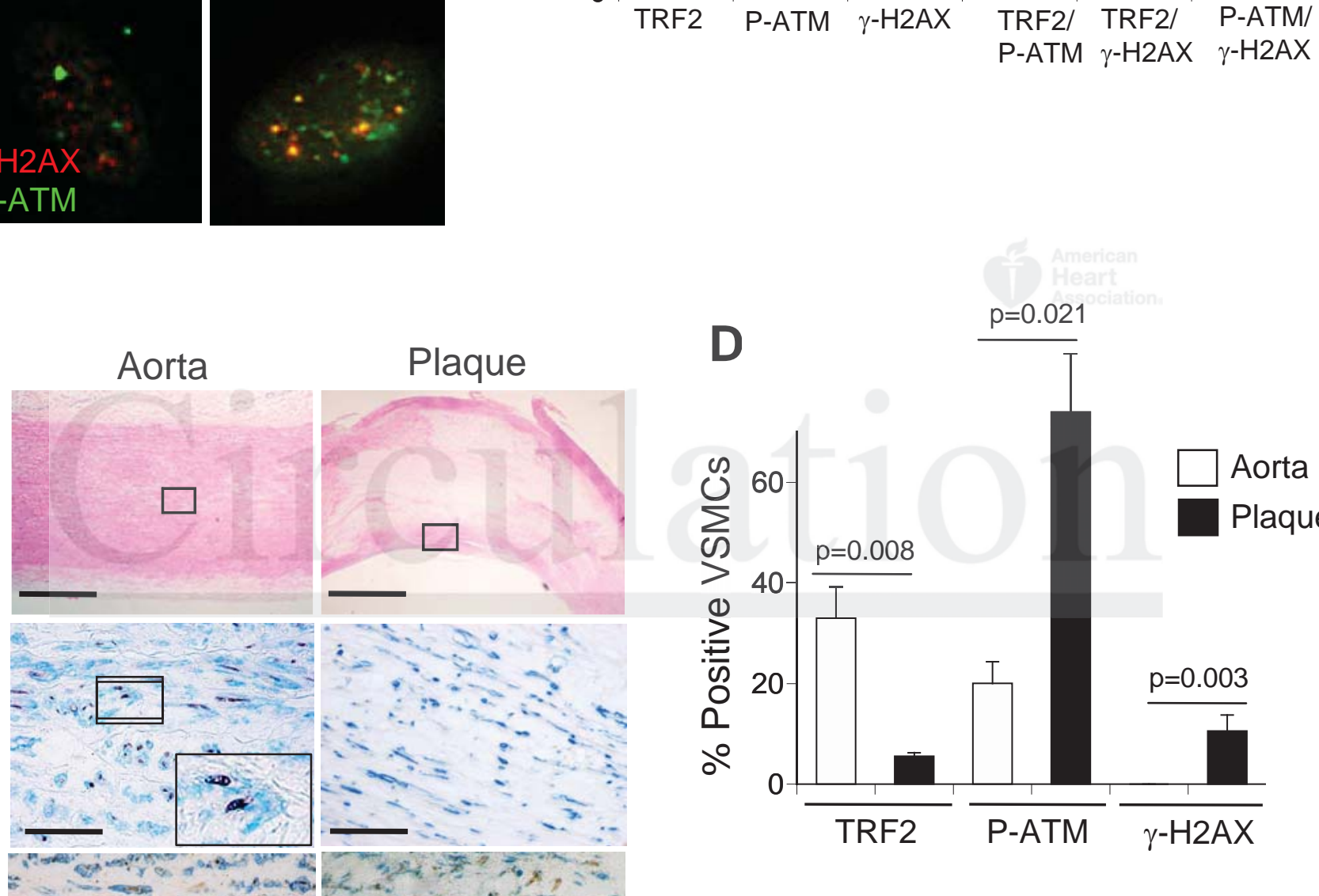

P-ATM
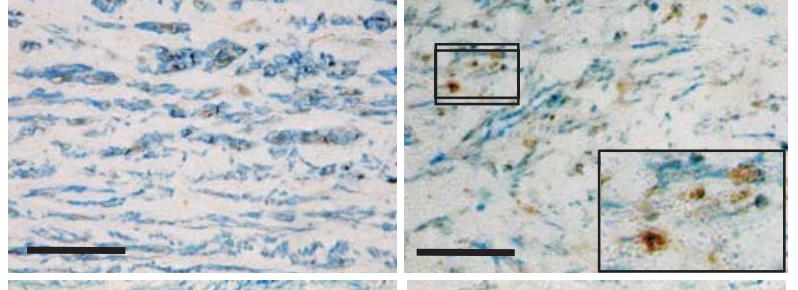

SMA
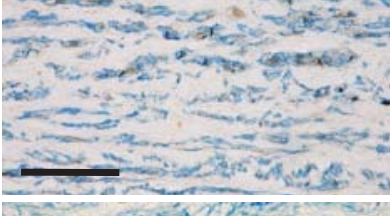

$\gamma-\mathrm{H} 2 \mathrm{AX}$

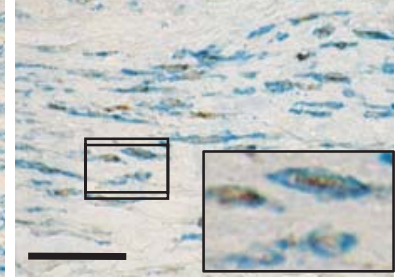




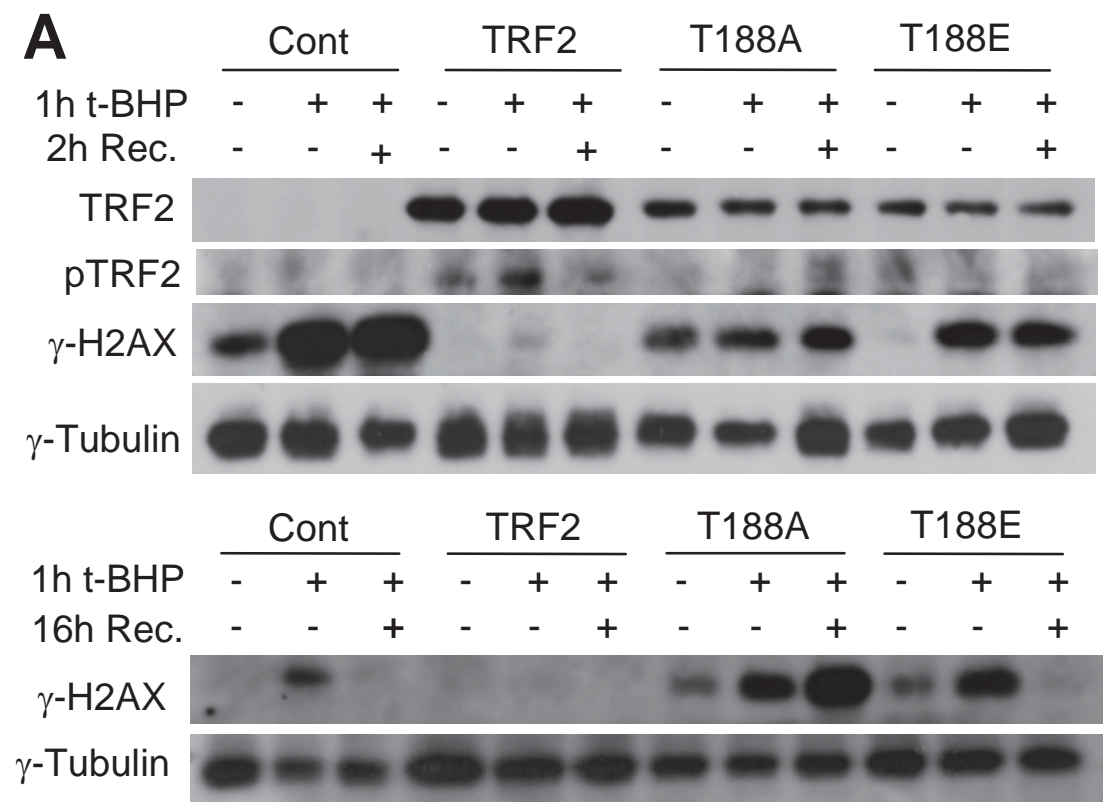

B
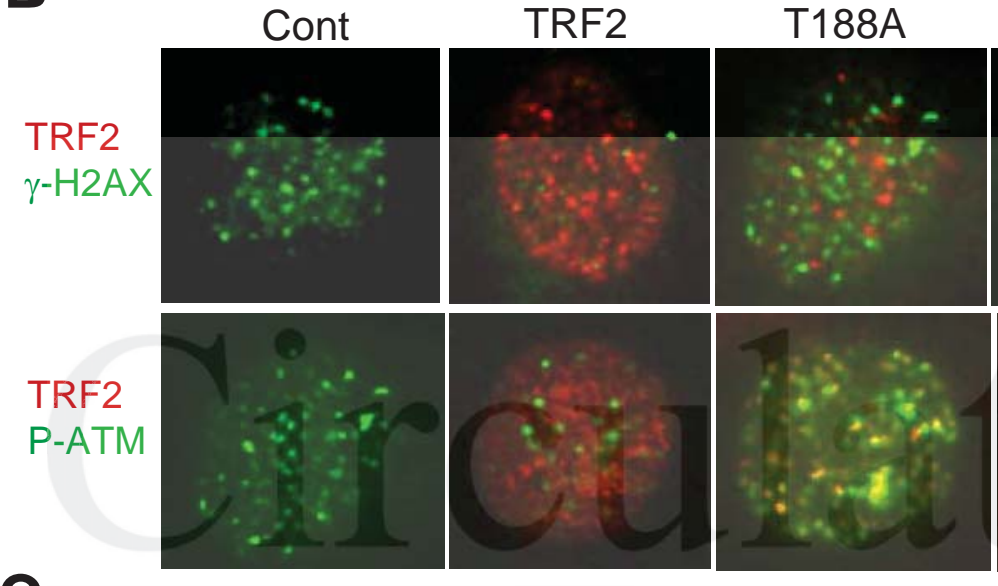

T188E

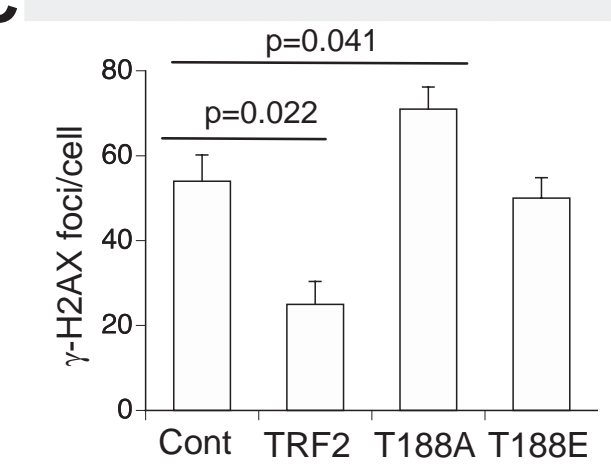

D

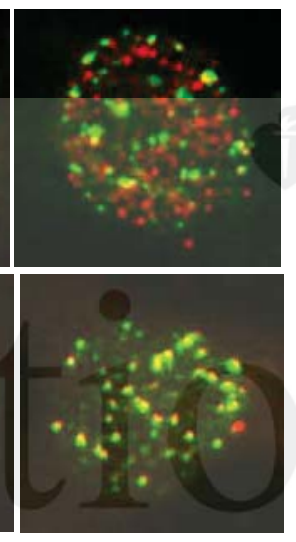

E
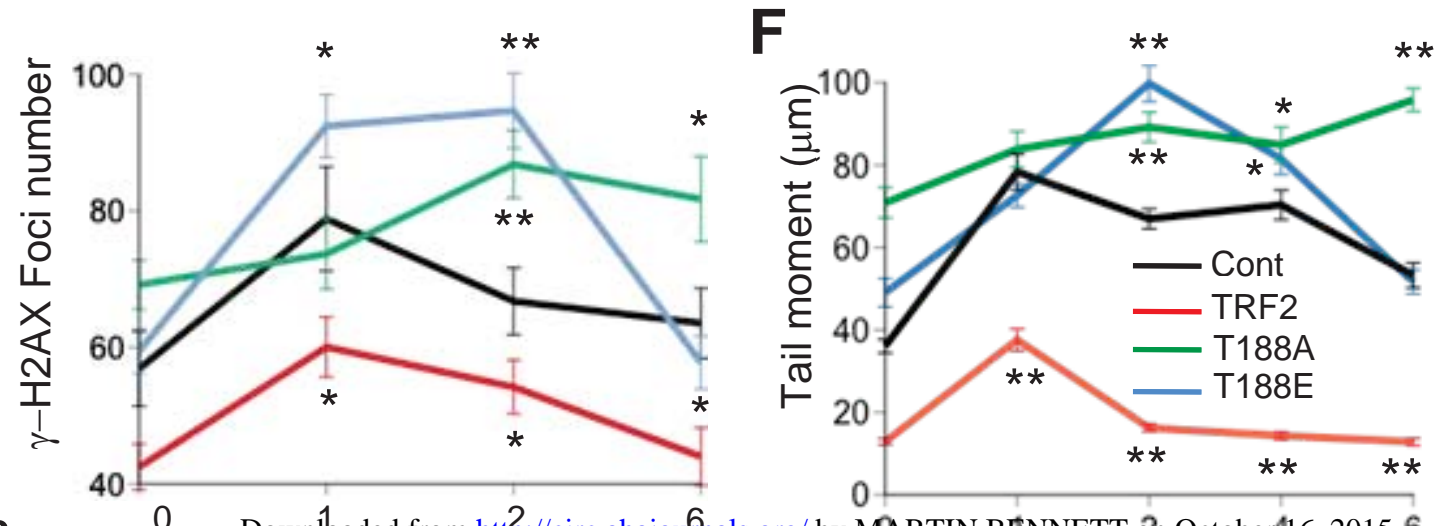
Hours 
A

\begin{tabular}{|c|c|c|c|c|c|}
\hline \multirow[b]{2}{*}{ Mice } & \multicolumn{3}{|c|}{ Aorta } & \multicolumn{2}{|c|}{ Gut } \\
\hline & 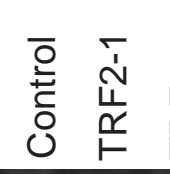 & 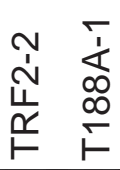 & 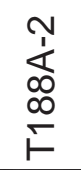 & 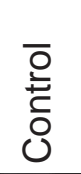 & 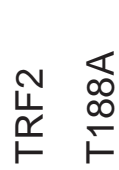 \\
\hline TRF2 & $\infty$ & $0=$ & $\ldots$ & & \\
\hline Actin & & & & & \\
\hline
\end{tabular}
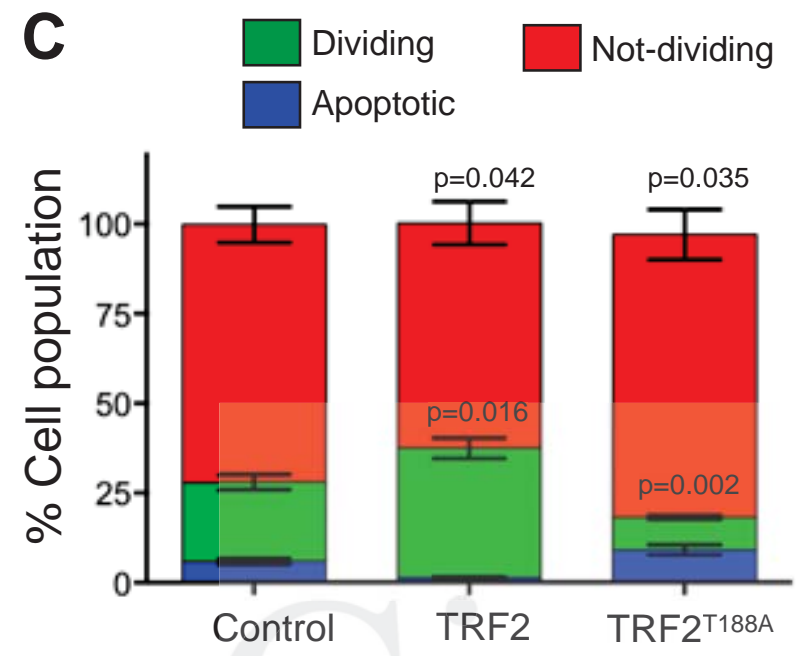

E Control TRF2 TRF2 ${ }^{\text {T188A }}$

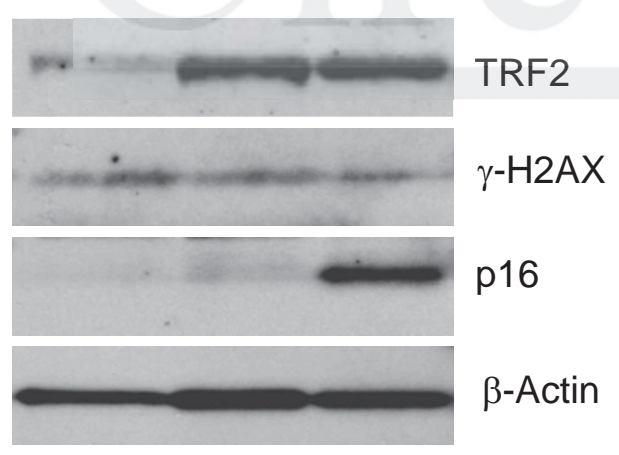

B
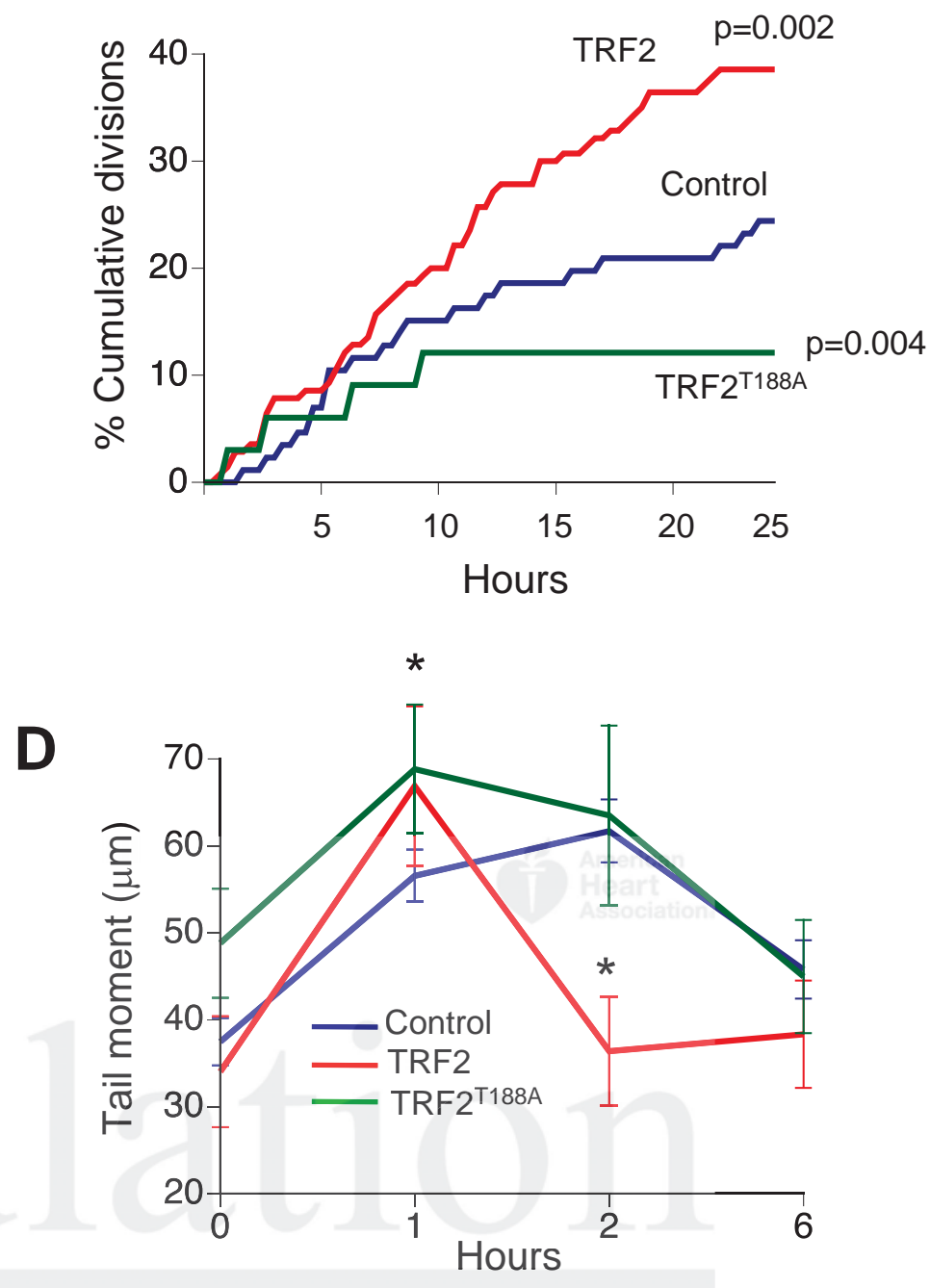


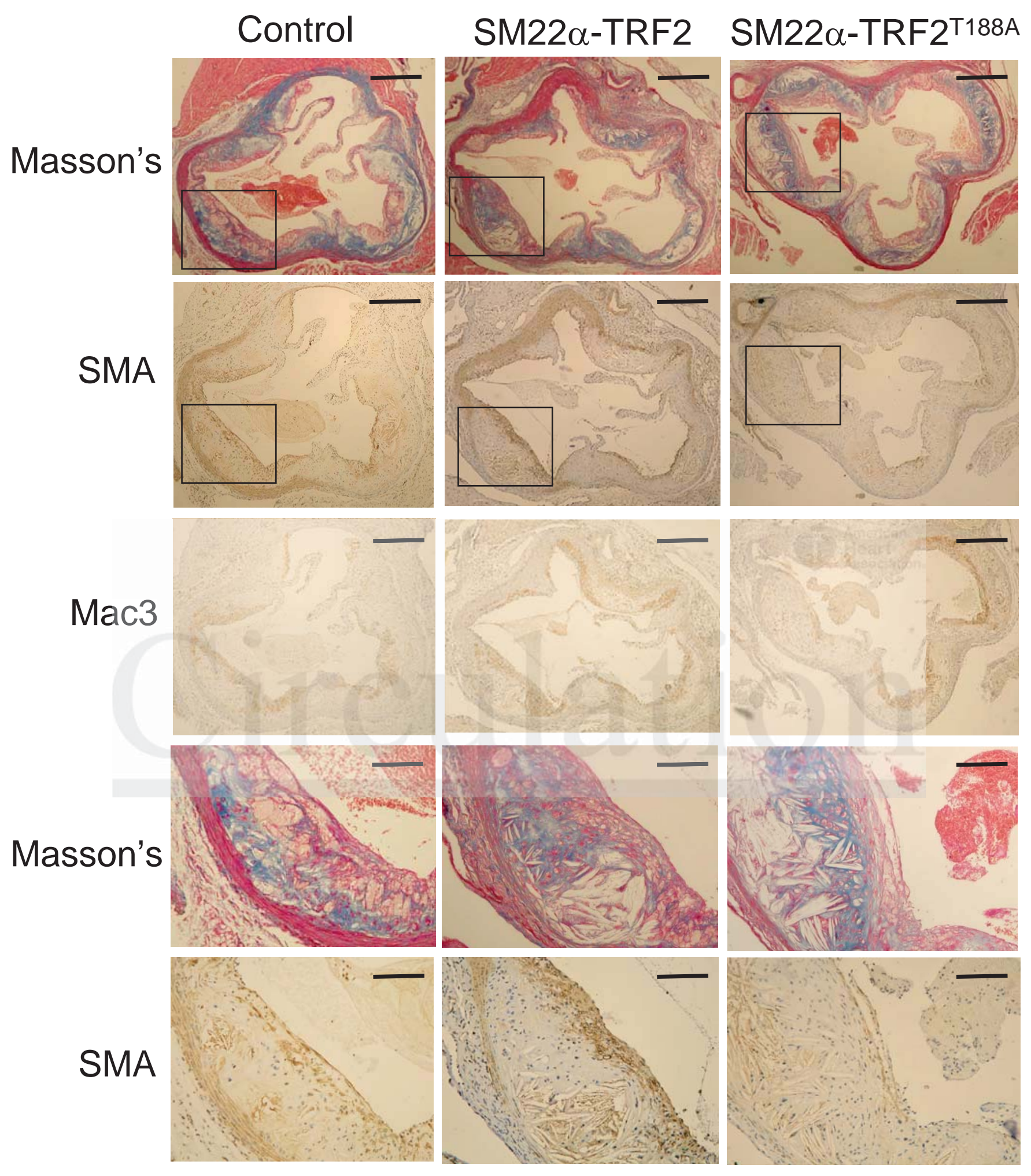


A
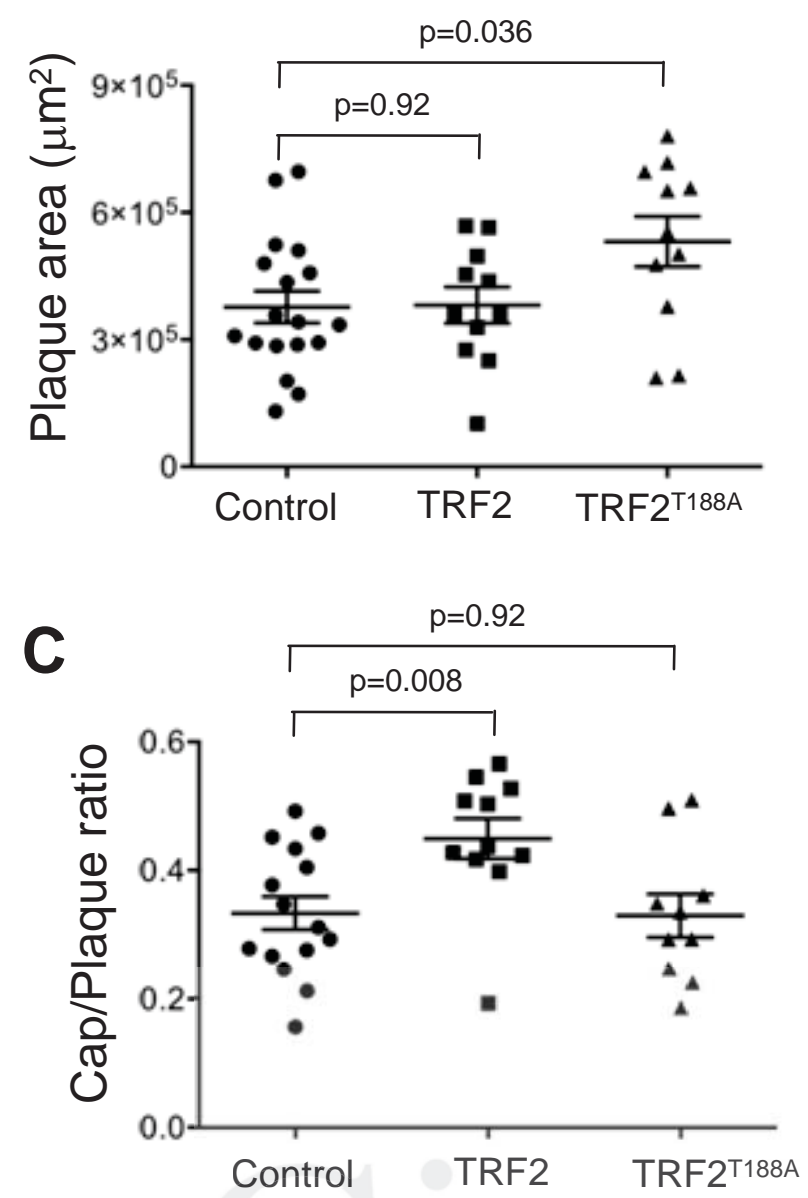

E

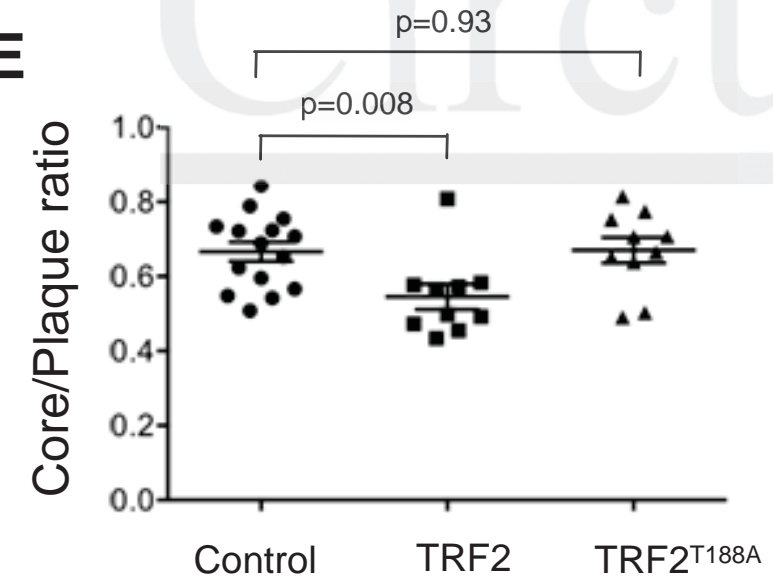

B
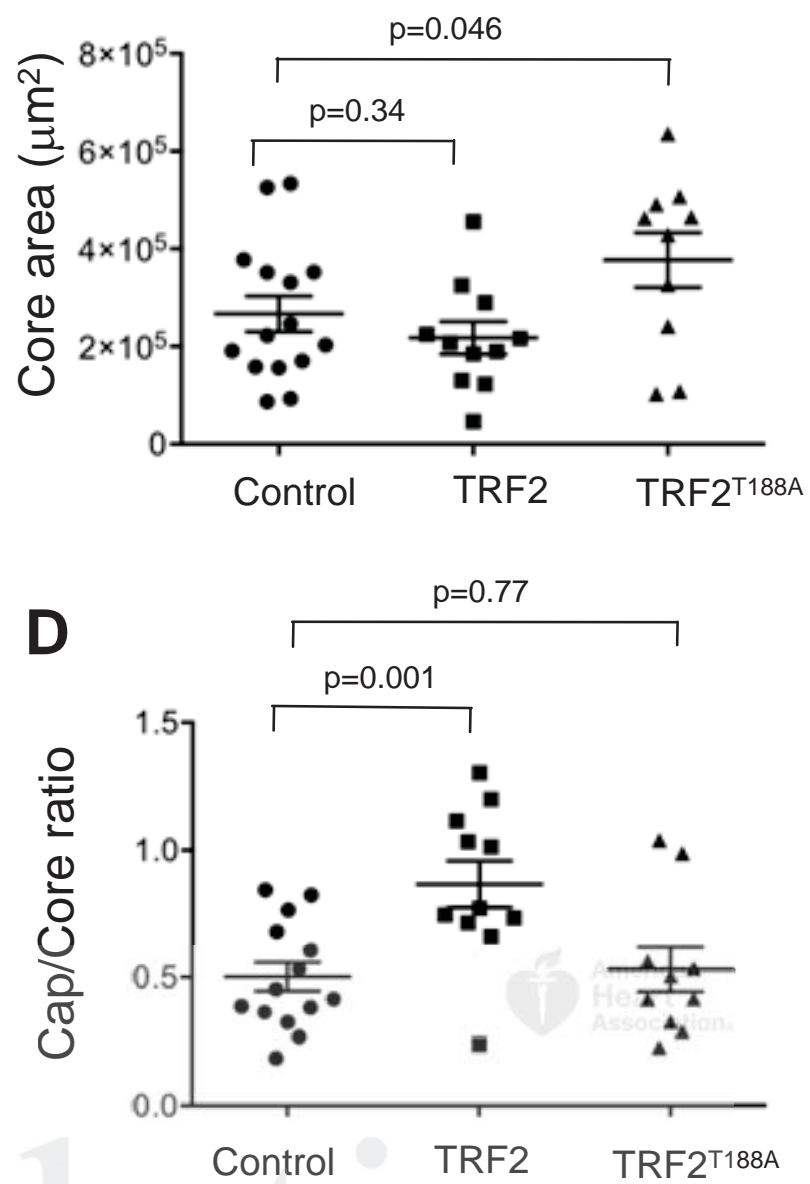


\section{Mitogens}

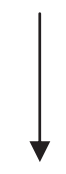

Replication

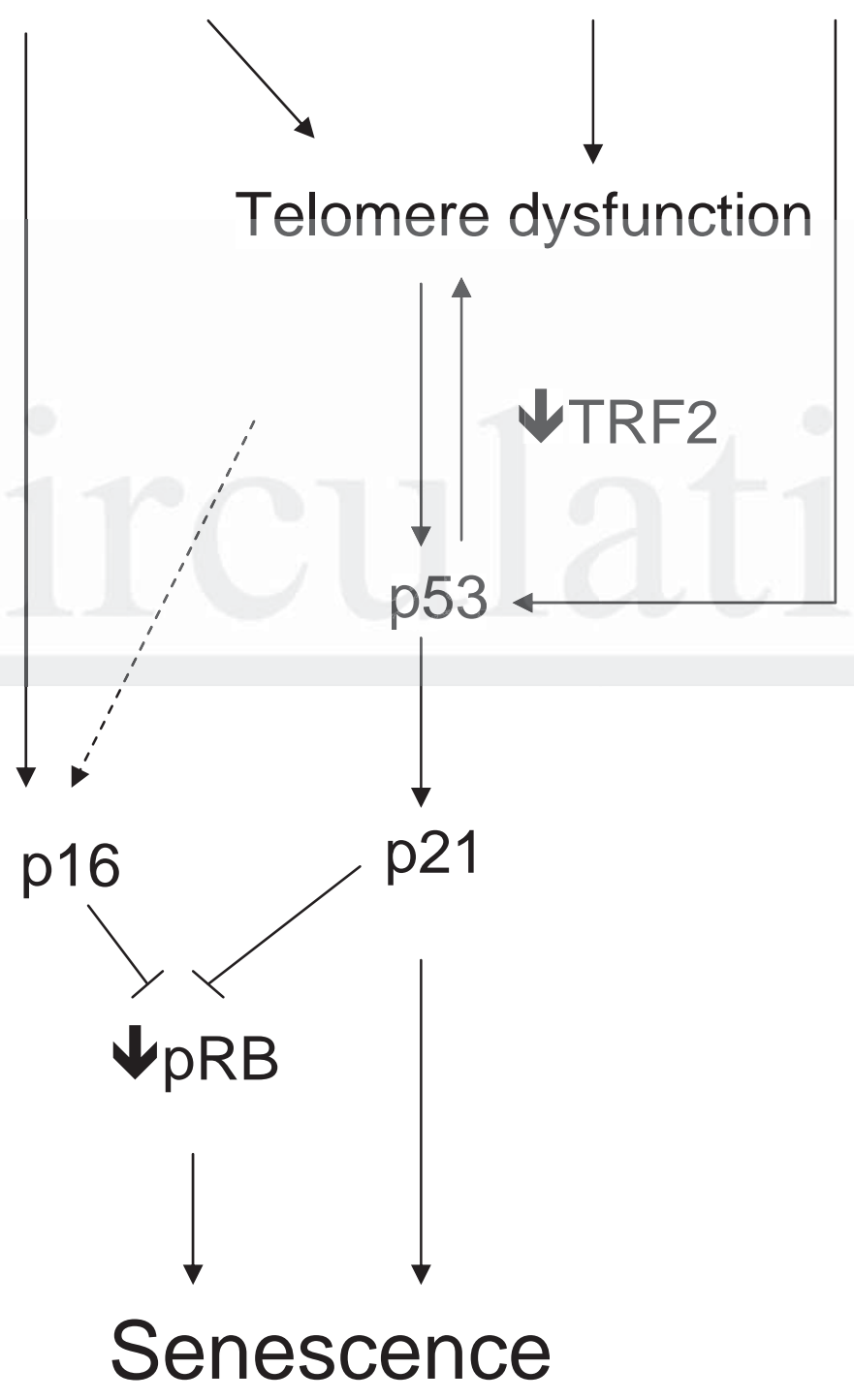

Figure 7 


\section{SUPPLEMENTAL MATERIAL}

\section{Supplemental Methods}

\section{Protein Extraction, Western blotting}

Protein extraction from cultured cells and Western blotting were performed as previously described $^{1}$. Tissue was dissected into $25 \mathrm{mg}$ pieces with 3 additional freeze-thaw cycles in lysis buffer in liquid nitrogen prior to incubation on ice for 12 minutes. Proteins were then extracted as per cultured cells. Primary antibodies were used as follows: mouse-TRF1 (\#3529,1:200; Cell Signalling Technology), rabbit-POT1 (ab21382), mouse-TIN2 (ab13791), mouse-RAP1 (ab14404) (all 1:5000; Abcam), mouse-TPP1 (B01; Abnova), rabbit- $\gamma-\mathrm{H} 2 \mathrm{AX}-$ ser139 (\#2577), rabbit-TRF2 and mouse-TRF2 (D1Y5D)(\#2645 and \#13136), rabbit- $\gamma$ Tubulin (\#2144), mouse-p53 (\#2524; 1C12) (all 1:1000; Cell Signaling Technology) and rabbit-p16-INK4A (10883-1-AP, 1:5000; Proteintech). Goat-siah1 (1:1000; ab2237; Abcam), HRP-conjugated secondary antibodies were sheep anti-mouse (1:2000; GE Healthcare) and donkey anti-rabbit (1:5000; GE Healthcare) in 1\% BSA/TBST.

\section{ChIP}

TRF2 association with telomeres was examined by ChIP. In brief, $1-5 \times 10^{6}$ cells were fixed in $1 \%$ formaldehyde for $10 \mathrm{~min}$ at room temperature. The reaction was quenched with $125 \mathrm{mM}$ glycine. Cross-linked cells were scraped, centrifuged and incubated in lysis buffer (1\% SDS, 10mM EDTA pH 8.0, 50mM Tris pH 8.1 and protease inhibitors (Roche)) on ice for $10 \mathrm{~min}$. The lysate was then sonicated (Diagenode Bioruptor ${ }^{\circledR}$ Standard) to shear chromatin and $50 \mu \mathrm{g}$ of chromatin used for immunoprecipitation. Samples were incubated overnight at $4^{\circ} \mathrm{C}$ with either anti-TRF2 (\#2645, 1:100, Cell Signalling Technologies) or equivalent isotype control (Santa Cruz Biotechnology). Following immunoprecipitation, $40 \mu \mathrm{L}$ of protein A dynabeads (Life Technologies) were added to samples and rotated for $1 \mathrm{~h}$. Beads/chromatin complexes were washed with low salt buffer (2X), high salt buffer (2X), $\mathrm{LiCl}$ buffer (1X) and TE buffer $(2 \mathrm{X})$ and immunocomplexes eluted at $65^{\circ} \mathrm{C}$ with $10 \%$ SDS and $1 \mathrm{mM} \mathrm{NaHCO} 3$ buffer. After addition of $40 \mathrm{mM} \mathrm{NaCl}$ and formaldehyde, cross-linking was reversed at $65^{\circ} \mathrm{C}$ 
overnight. DNA was recovered using a mini-elute DNA purification kit (Qiagen). Telomere specific real-time PCR was performed as previously described ${ }^{2}$.

\section{Immunocytochemistry}

Immunocytochemistry for nuclear foci was performed as described previously ${ }^{1}$. Primary antibodies were rabbit anti- $\gamma-\mathrm{H} 2 \mathrm{AX}{ }^{\text {ser139 }}$, P-ATM, and TRF2 (\#9718, \#4526 and \#2645, all 1:100, Cell Signaling Technologies). Secondary antibodies were Alexa Fluro488 goat antimouse IgG and Alexa Fluro694 Goat anti-rabbit IgG (1:500; Invitrogen). $\gamma$-H2AX ${ }^{\text {ser139 }}$ foci intensity was assayed using Image $(\mathrm{NIH})$

\section{Immunohistochemistry}

Immunohistochemistry of human and mouse arteries was performed as described previously $^{3}$

\section{Cell Culture}

Mouse cell lines were cultured in DMEM supplemented with 10U/ml Penicillin (Sigma), $10 \mu \mathrm{g} / \mathrm{ml}$ Streptomycin (Sigma), $5 \mu \mathrm{g} / \mathrm{ml}$ L-Glutamine (Sigma), $10 \%$ fetal calf serum (Sigma) \pm hygromycin. Cells were treated with t-butyl hydroperoxide (t-BHP, $100 \mu \mathrm{M})$ for 1 hour at $80 \%$ confluency prior to analysis at selected time points.

\section{Measurement of Telomere Length (Q-PCR)}

The length of mouse telomeres was measured by Q-PCR on a Rotor-Gene (Corbett Research) PCR platform. The single-copy control gene (36B4) was measured using forward and reverse primers 5' ACT GGT CTA GGA CCC GAG AAG 3' and 5' TCA ATG GTG CCT CTG GAG ATT 3', respectively. The primers used to measure average telomere length were 5' CGG TTT GTT TGG GTT TGG GTT TGG GTT TGG GTT TGG GTT 3' and 5' GGC TTG CCT TAC CCT TAC CCT TAC CCT TAC CCT TAC CCT 3'. The master mix reaction for 
36B4 contained 10 $\mu$ I SYBR Green JumpStart Taq ReadyMix (Sigma), 20ng purified DNA in $5 \mu \mathrm{l}, 300 \mathrm{nM}$ forward primer, $500 \mathrm{nM}$ reverse primer and PCR-grade $\mathrm{H}_{2} \mathrm{O}$ (Invitrogen) in a 20 $\mu \mathrm{l}$ final volume. The reaction mix for telomere length was similar to 36B4, except using 300nM of both forward and reverse primers. qPCR reaction conditions were $95^{\circ} \mathrm{C}$ for 15 minutes, followed by 35 cycles of elongation steps starting at $95^{\circ} \mathrm{C}$ for 15 seconds, $54^{\circ} \mathrm{C}$ for 60 seconds and $72^{\circ} \mathrm{C}$ for 30 seconds, and finished at $72^{\circ} \mathrm{C}$ for 10 minutes. ApoE ${ }^{-/-}$mouse DNA, serially diluted from $60 \mathrm{ng}$ to $1.875 \mathrm{ng}$, was used to generate a reaction standard curve. Each DNA sample was run in triplicate and two negative controls (no template DNA; no primers) were run in duplicate in parallel. The input amounts of telomere and 36B4 DNA were calculated based on the standard curve generated after averaging the threshold cycle number $(\mathrm{Ct})$ values for each sample. The average telomere length ratio (ATLR) was then calculated by dividing the amount of telomeric DNA to the amount of 36B4 product.

\section{Chromosome harvest and and telomere FISH}

To prepare metaphase chromosomes, mouse VSMCs were treated with $0.03 \mu \mathrm{g} / \mathrm{mL}$ of Colcemid (Gibco, Life Technologies) for $16 \mathrm{~h}$, followed a buffered hypotonic solution $(0.4 \%$ $\mathrm{KCl}$ in $10 \mathrm{mM}$ HEPES, $\mathrm{pH} 7.4$ ) for $8 \mathrm{~min}$ at $37^{\circ} \mathrm{C}$. The cells were centrifuged and resuspended in $4: 1(\mathrm{v} / \mathrm{v})$ methanol:glacial acetic acid and kept at $-20^{\circ} \mathrm{C}$ until use. Metaphase preparations were placed onto pre-cleaned microscope slides. Telomere FISH with a Cy3TelC PNA probe was performed following the manufacturer's protocol (PNA Bio inc.). Digital images were captured on a Leica DM5000 B microscope equipped with an ORCA-03G CCD camera (Hamamatsu) controlled by SmartCapture software (Digital Scientific UK).

\section{Analysis of Atherosclerosis}

Atherosclerosis extent and composition was analyzed as described previously ${ }^{4}$ Briefly, sections from the aortic root and brachiocephalic arteries were stained with H\&E, $\alpha-S M A$, 
Mac3, and TUNEL. Plaque extent and composition was measured using CellD analysis software. The fibrous cap and necrotic core was defined using Masson's Trichrome. 


\section{Supplemental Figures}

A

B
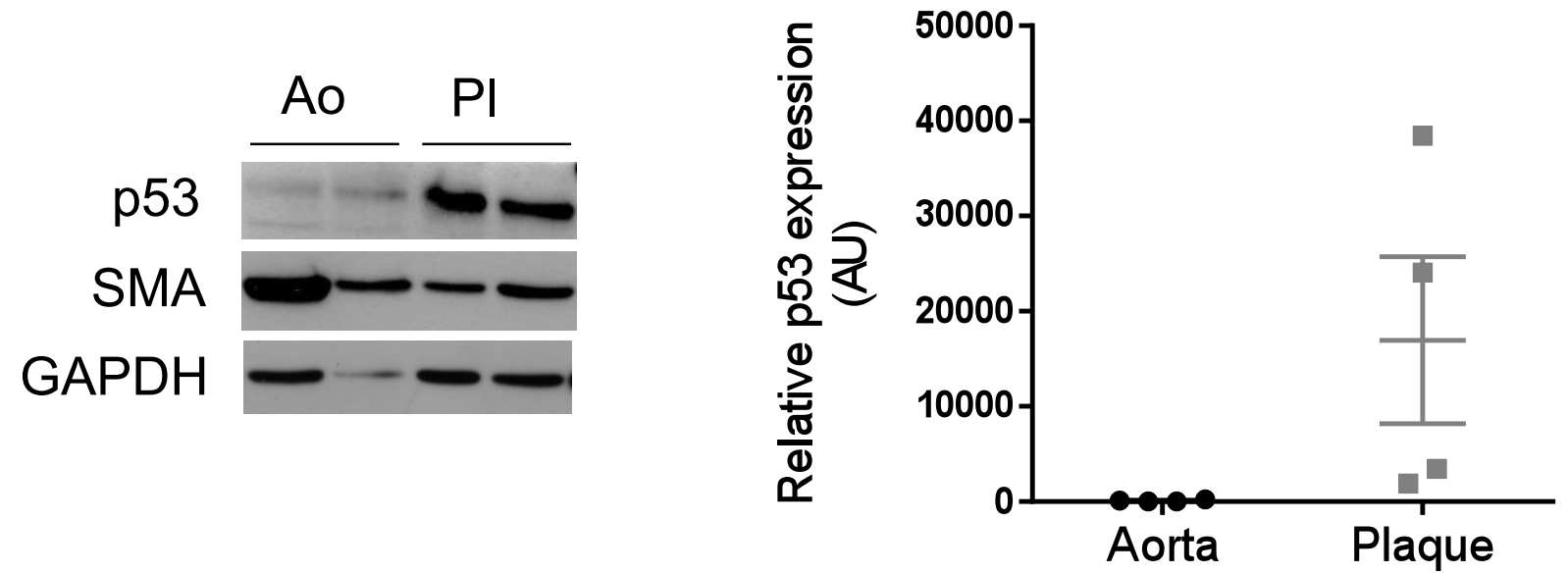

C

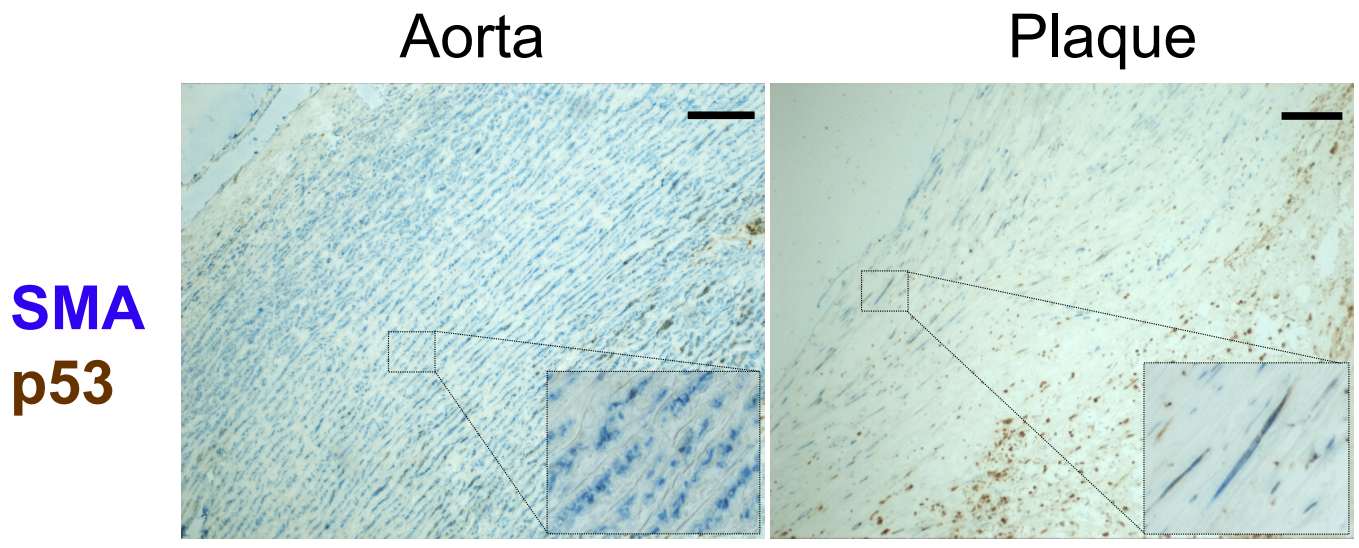

D

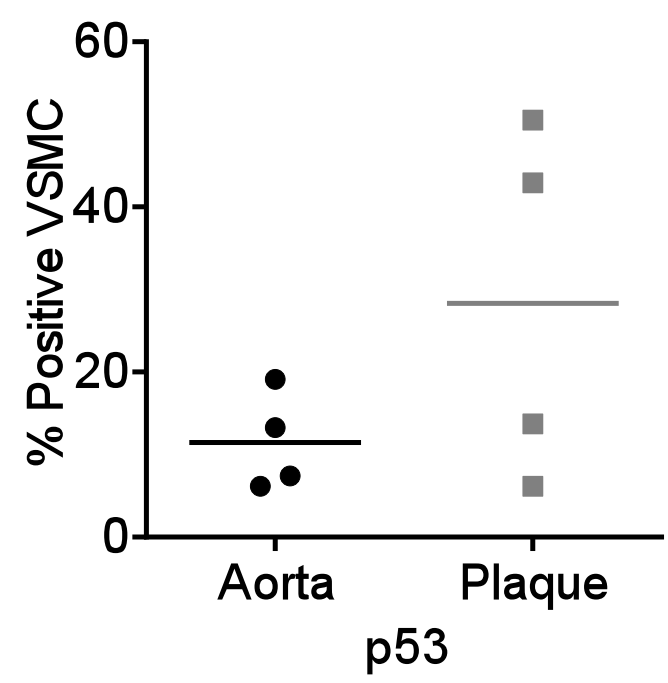

Supplemental Figure 1

(A) Western blot for p53 and SMA of whole lysates from normal human aorta (Ao) or carotid plaque (PI). (B) Quantification of Western blots from aortic or plaque lysates. $n=4$. (C) Immunohistochemistry for p53 or SMA in normal human aorta or carotid plaque. Scale bars $=150 \mu \mathrm{m}$. Insets show high power views of areas outlined. (D) Quantification of \% of VSMCs that express p53 in aortic or plaque sections. $n=4$. 


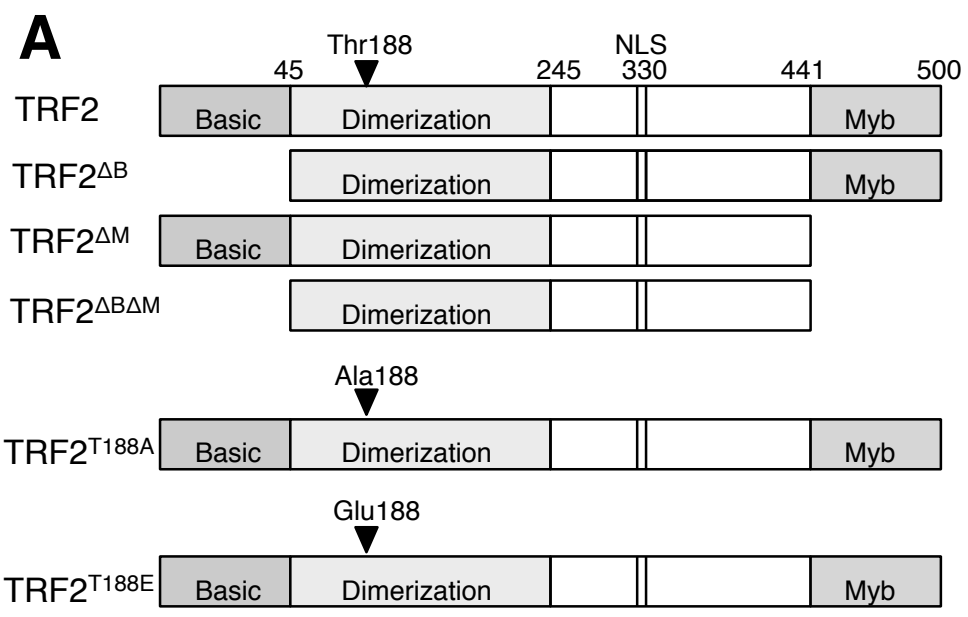

B

TRF2

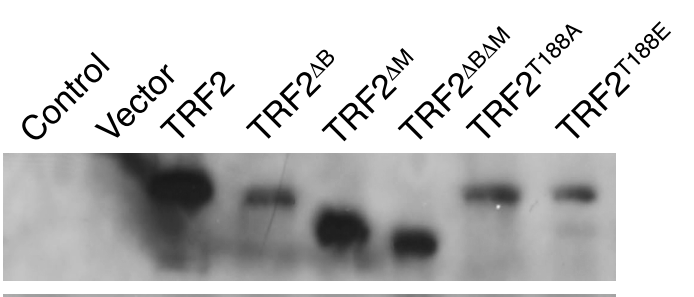

$\gamma$-Tubulin

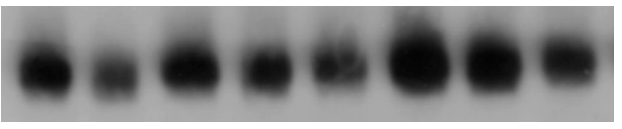

C

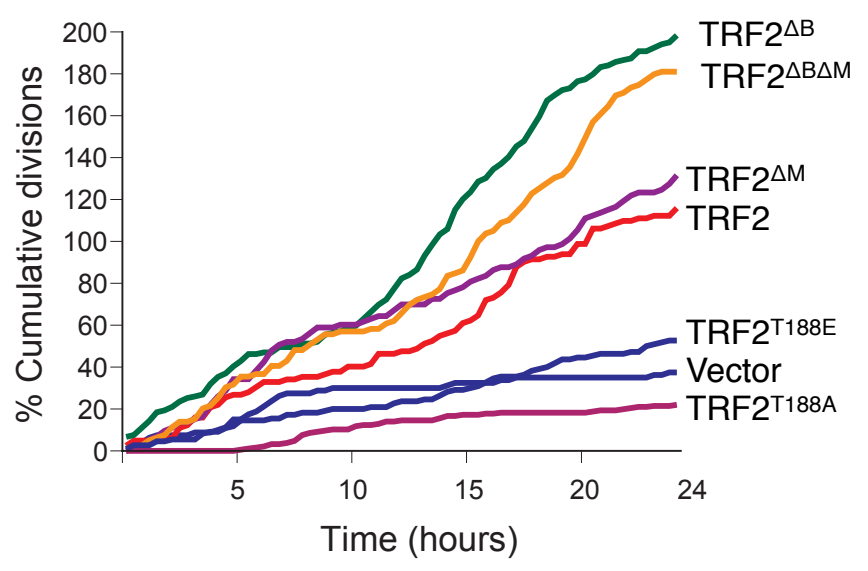

E

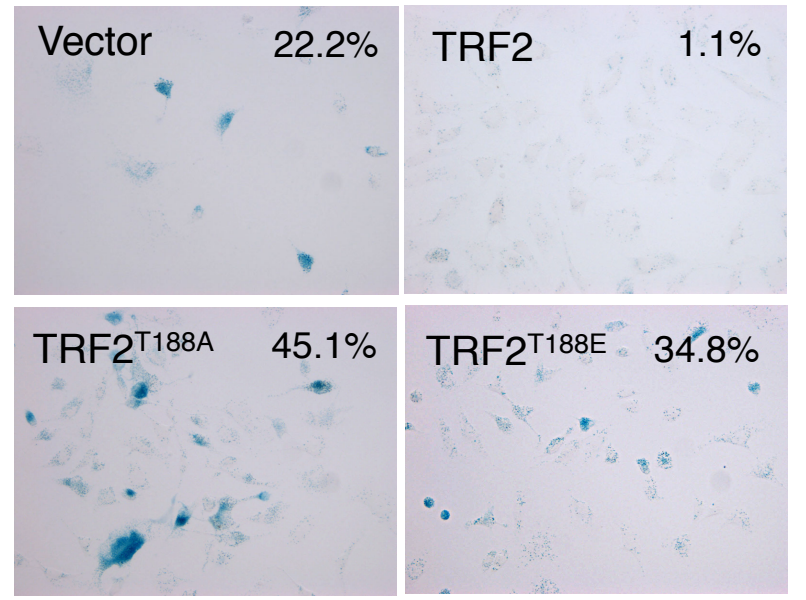

D

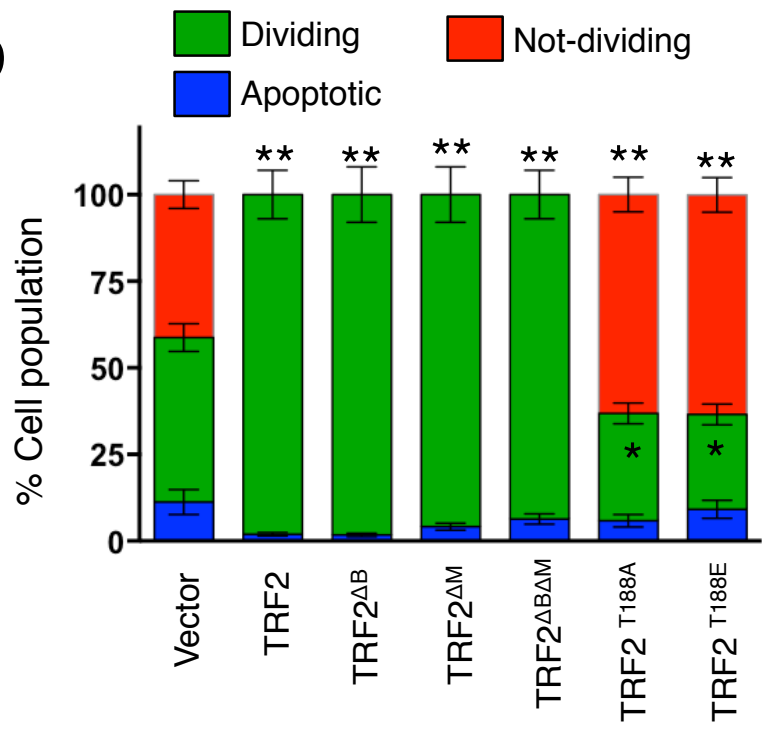

\section{Supplemental Figure 2}

(A) Schematic of TRF2 constructs. Basic, dimerization and myb domains, and nuclear localisation signal (NLS) are marked. (B) Western blot for TRF2 in ApoE ${ }^{-/-}$VSMC lines, including control (uninfected) and vector-infected VSMCs. (C) Time-lapse videomicroscopic analysis of \% cell proliferation over 24 hours in VSMC lines. (D) \% cells undergoing cell division, apoptosis or senescence in VSMC lines. Data are means \pm SD. (E). SA $\beta G$ expression in VSMC lines at passage 14 (vector) or passage 4 (TRF2, T188A/E)(Data are means, $n=3$ ). ${ }^{*} p<0.05$, ${ }^{* *} p<0.01$ vs. vector lines. 


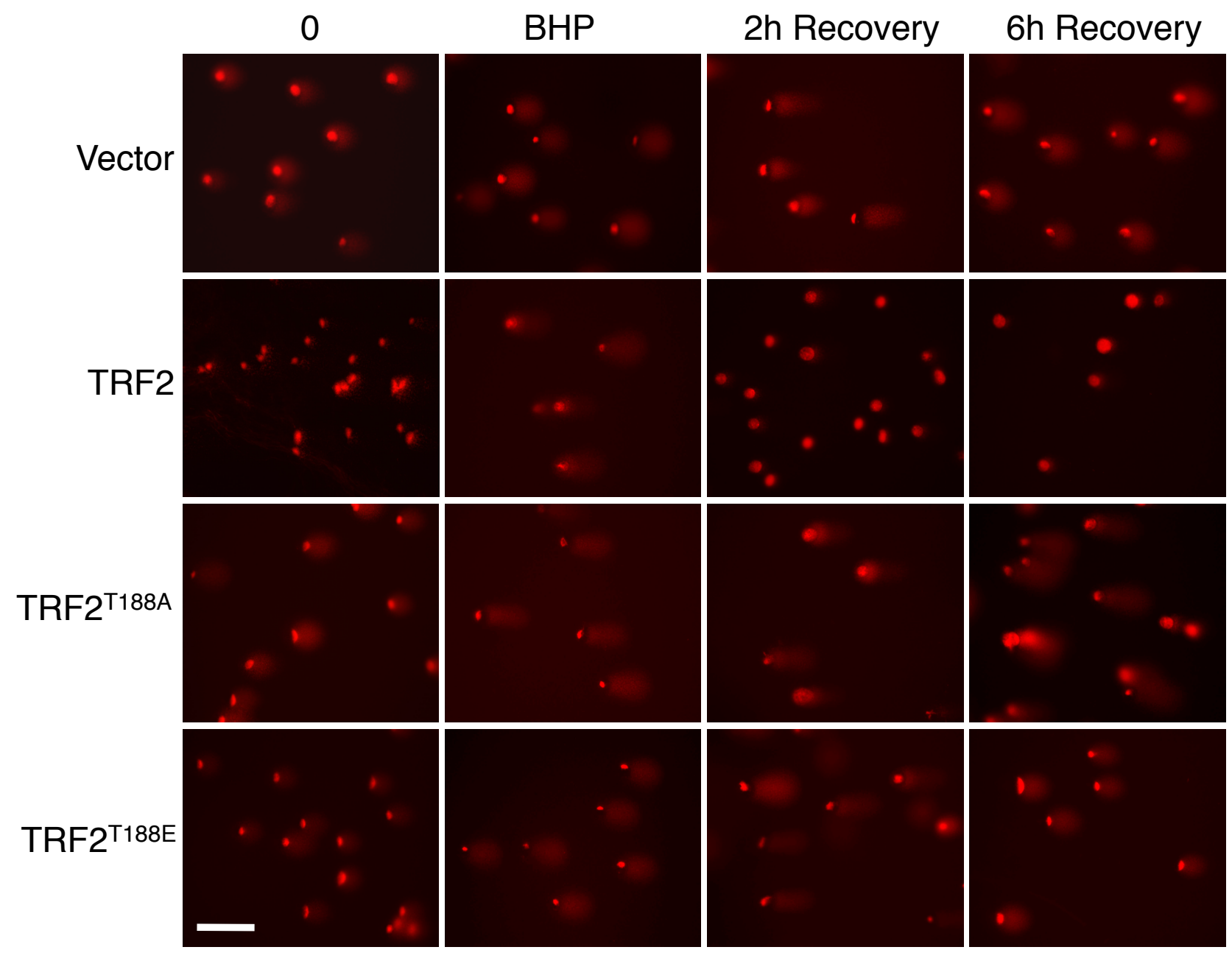

Supplemental Figure 3

Comet assay of VSMCs expressing vector alone, TRF2, TRF2 ${ }^{\text {T188A }}$ or TRF2 ${ }^{188 \mathrm{E}}$ at baseline (Time 0 ), $1 \mathrm{hr}$ of BHP treatment (BHP) and either 2 or 6 hours after removal of $\mathrm{BHP}$ (recovery). Scale bar $=25 \mu \mathrm{m}$. 

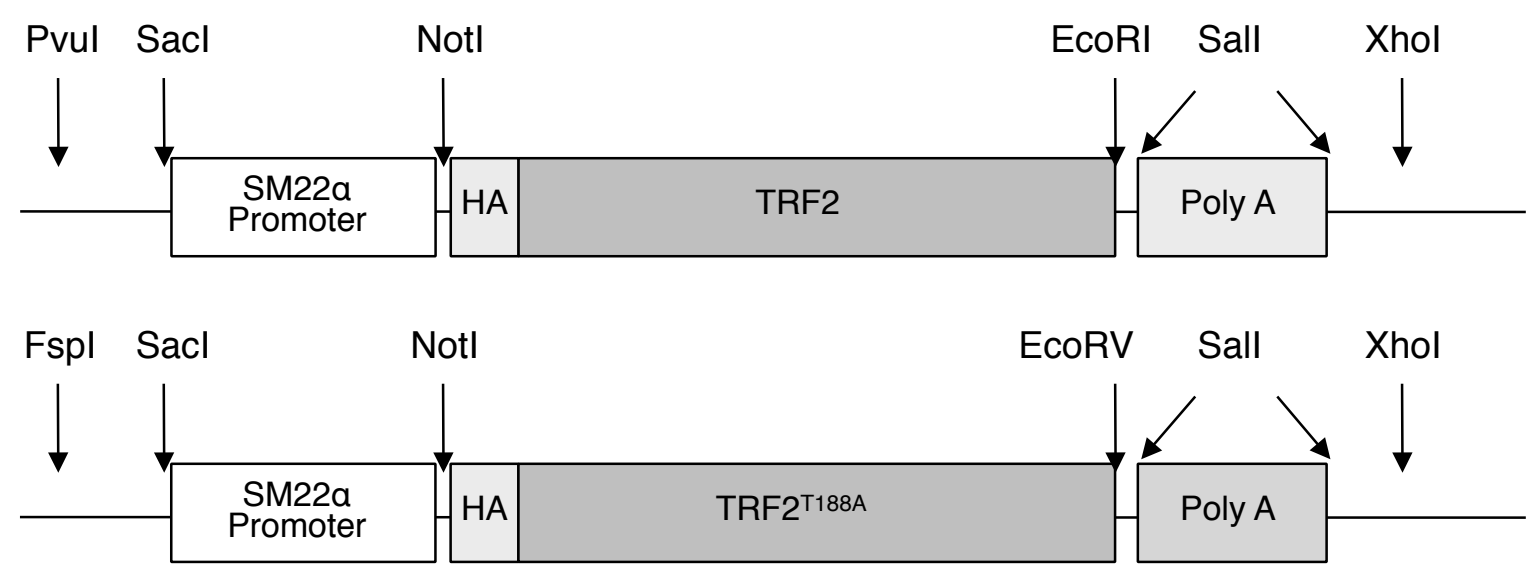

Supplemental Figure 4

Map of transgenic targeting constructs 

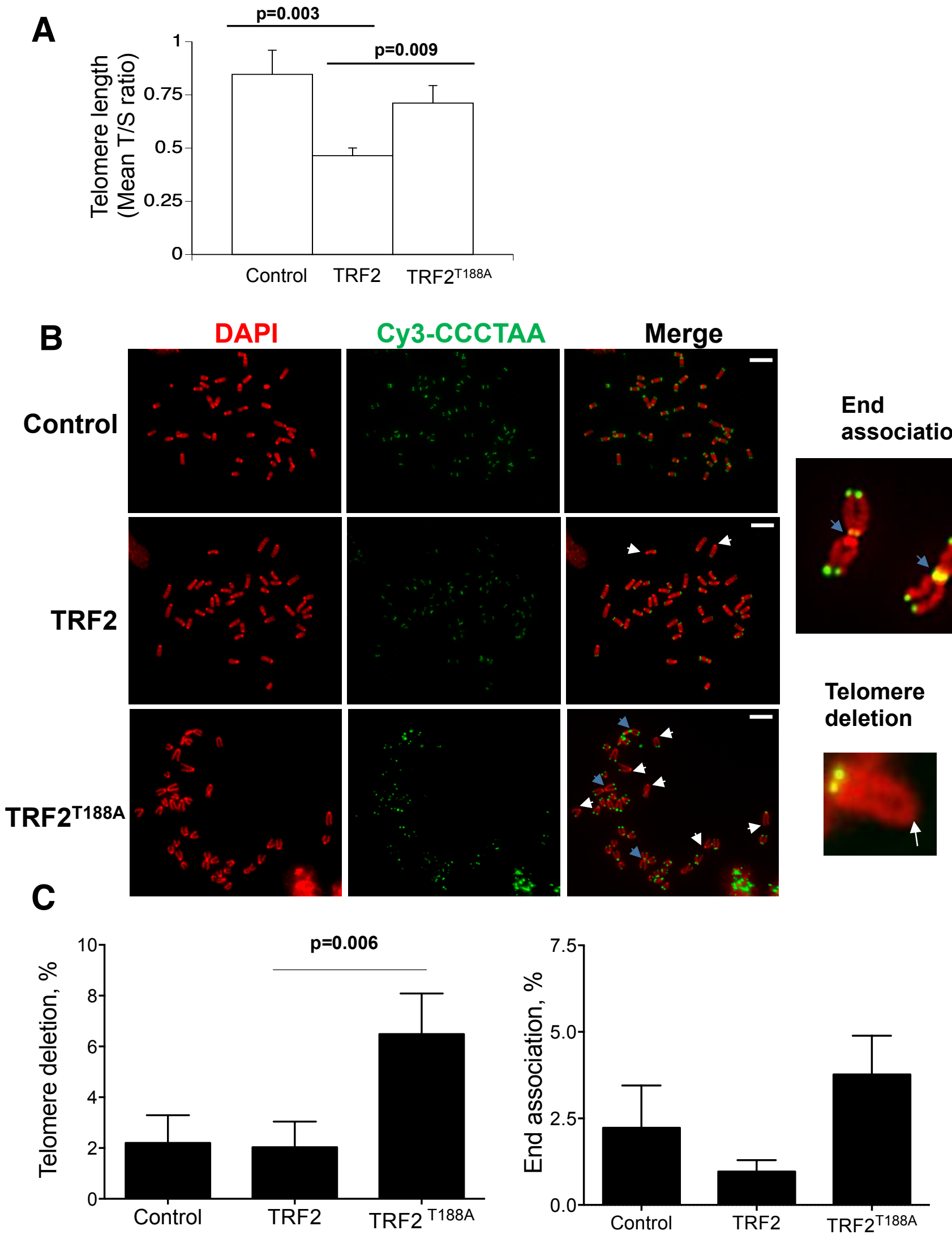

\section{Supplemental Figure 5}

(A) Telomere length in mouse ApoE-/-VSMCs (Control), SM22 $\alpha$-TRF2/ApoE ${ }^{-/-}$VSMCs (TRF2), or SM22 $\alpha-$

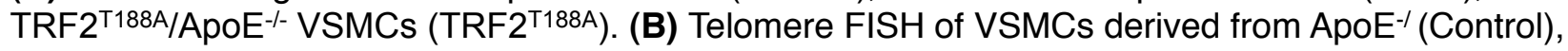
SM22 $\alpha-$ TRF2/ApoE $^{-/-}$(TRF2) and SM22 $\alpha-$ TRF2 $^{\text {T188A }} /$ ApoE $^{-/-}\left(\right.$TRF2 $\left.^{\text {T188A }}\right)$ mice. The Telomeric Cy3labelled synthetic PNA-(CCCTAA $)_{3}$ probe is shown in green and chromosomal counterstain (DAPI) in red. High magnification examples of end association and telomere deletions are shown on the right. White arrows indicate terminal deletion, blue arrows indicate end association. (C) Quantification of \% chromosomes showing end association or terminal deletion. Scale bar $=10 \mu \mathrm{M}$. Data are means $\pm S D$. ( $n=400-1000$ chromosomes/genotype). 
B
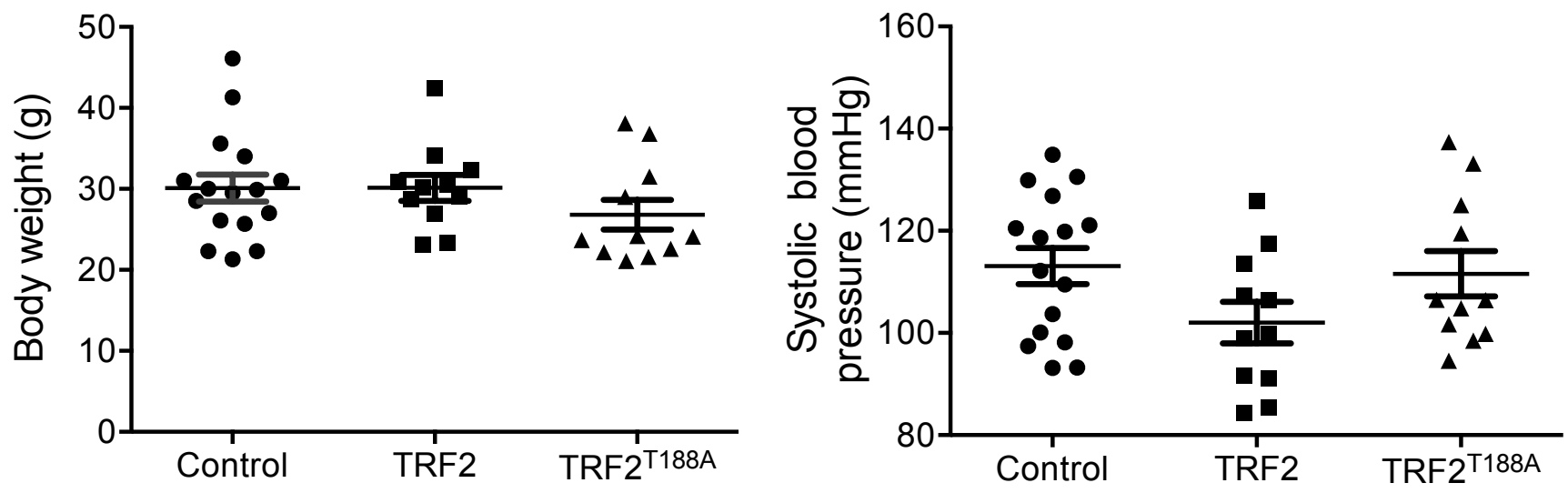

C
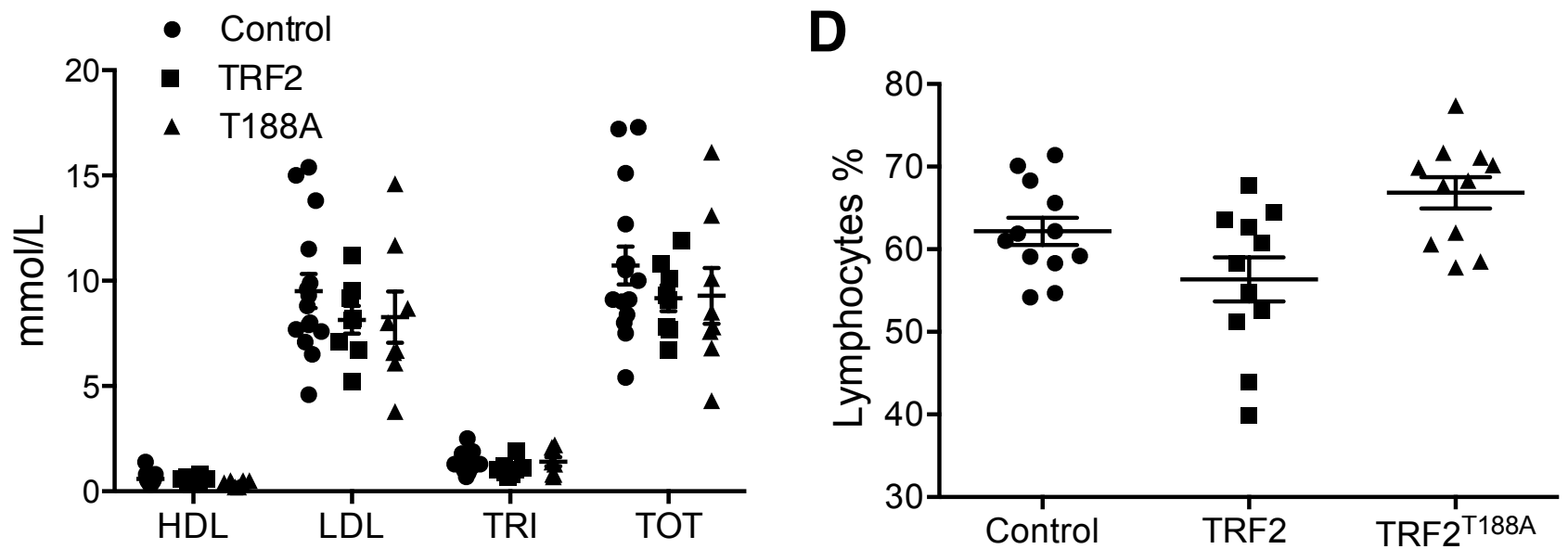

E

$\mathbf{F}$
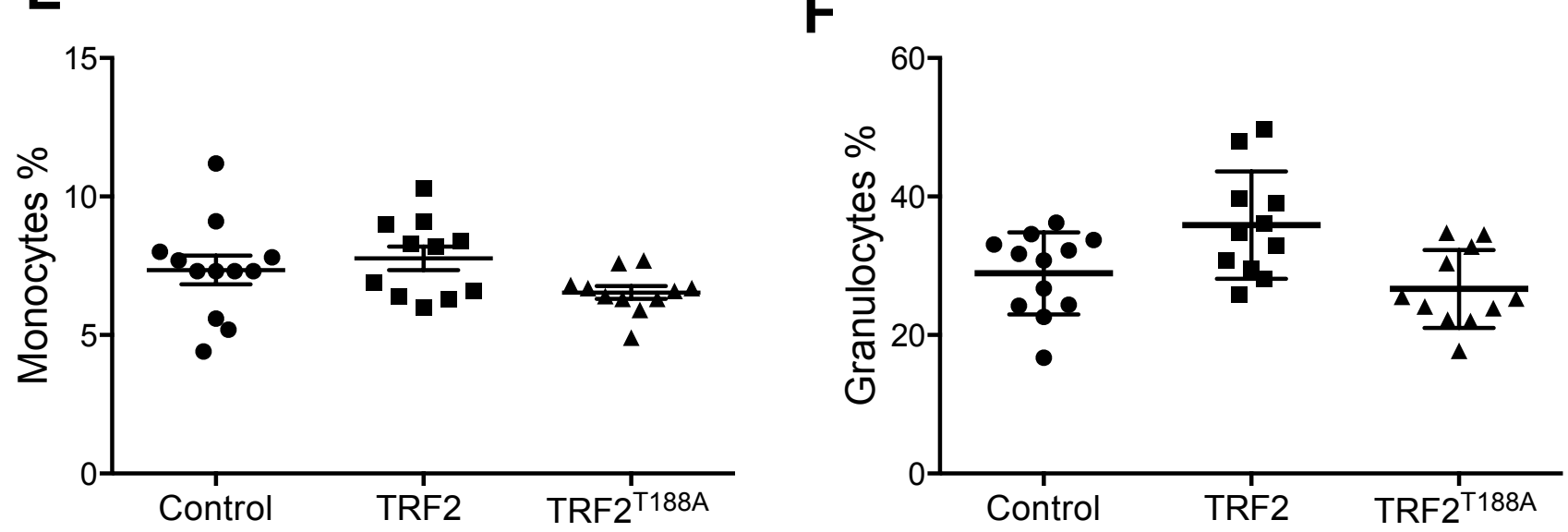

\section{Supplemental Figure 6}

(A-F) Body weight (A), blood pressure (B), serum high density lipoprotein (HDL), low density lipoprotein (LDL), Triglycerides (TRI) or total cholesterol (TOT) (C), and leukocyte counts (D-

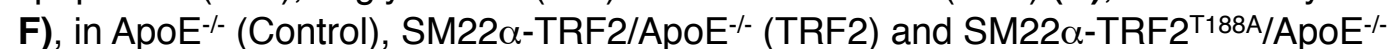
(TRF2 ${ }^{T 188 A}$ ) mice after fat feeding from 6-22w. Data are means \pm SEM, $n=8-12$. 
Control

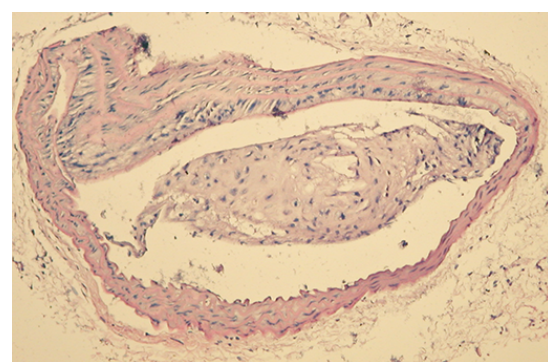

TRF2

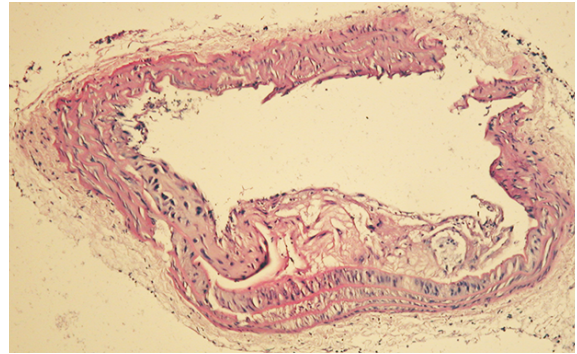

TRF2'188A

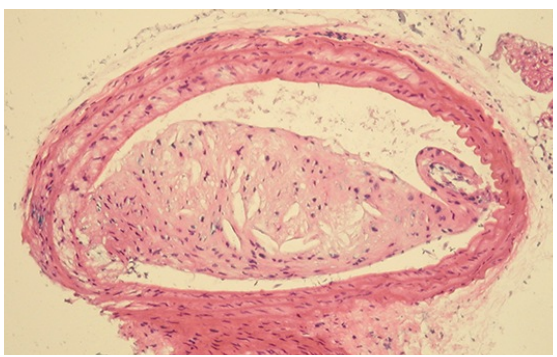

\section{Supplemental Figure 7}

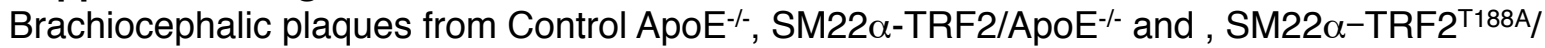
ApoE ${ }^{-/-}$mice after fat feeding from 6-22w.

A

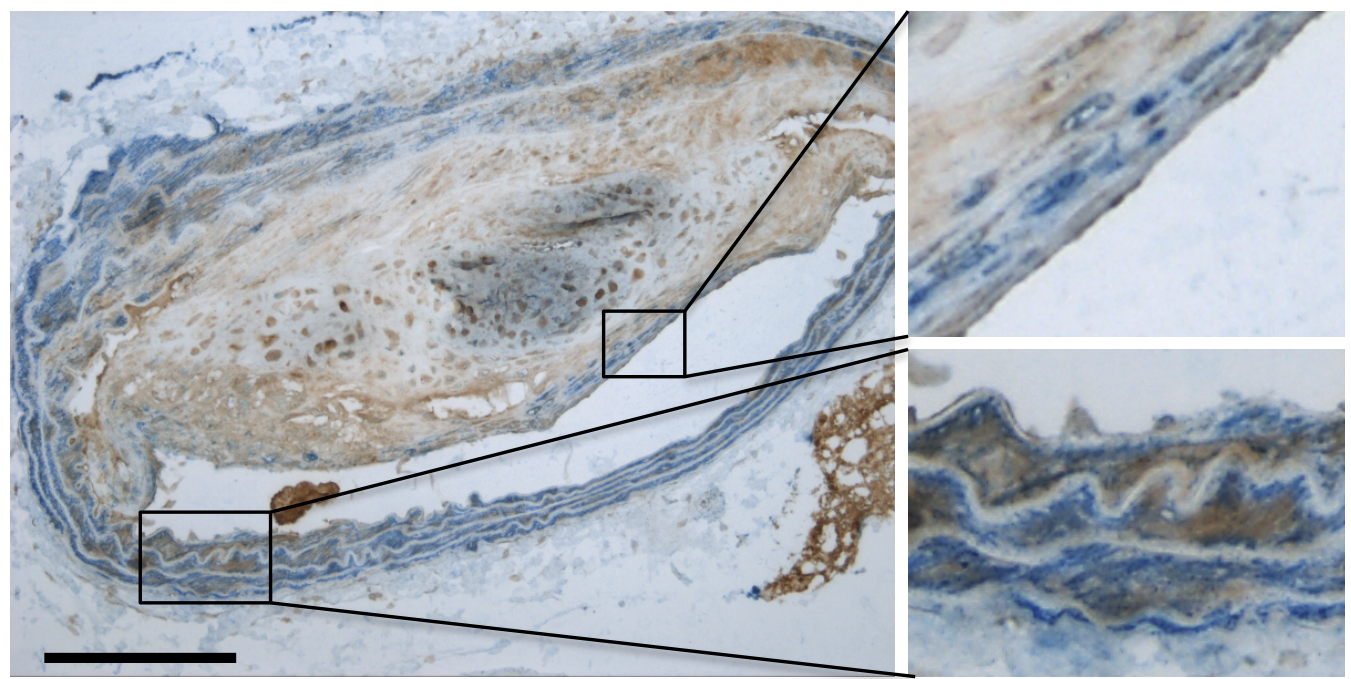

B

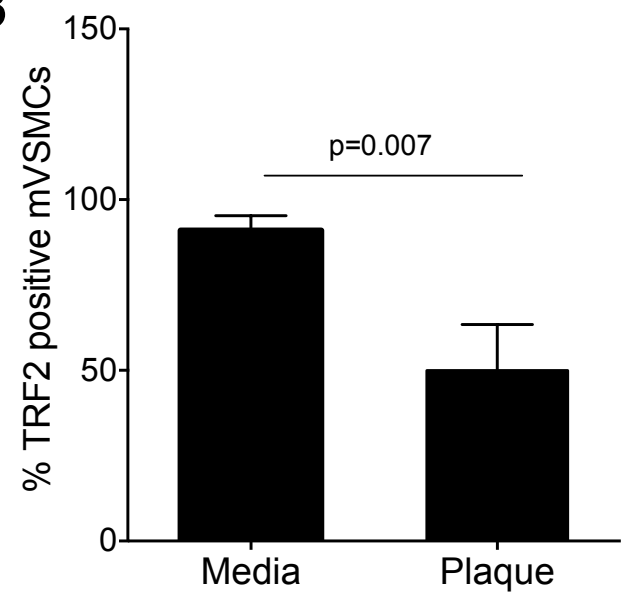

\section{Supplemental Figure 8}

(A) Immunohistochemistry for TRF2 (brown) and SMA (blue) in ApoE-/- mouse plaques or undiseased media. High power view of fibrous cap ormedial VSMCs are shown on the right. Scale bar $=150 \mu \mathrm{m}$. (B) Quantification of \%TRF-2-positive VSMCs in ApoE $\mathrm{E}^{-/-}$mouse plaques or undiseased media. Data are means $\pm S D(n=8)$. 

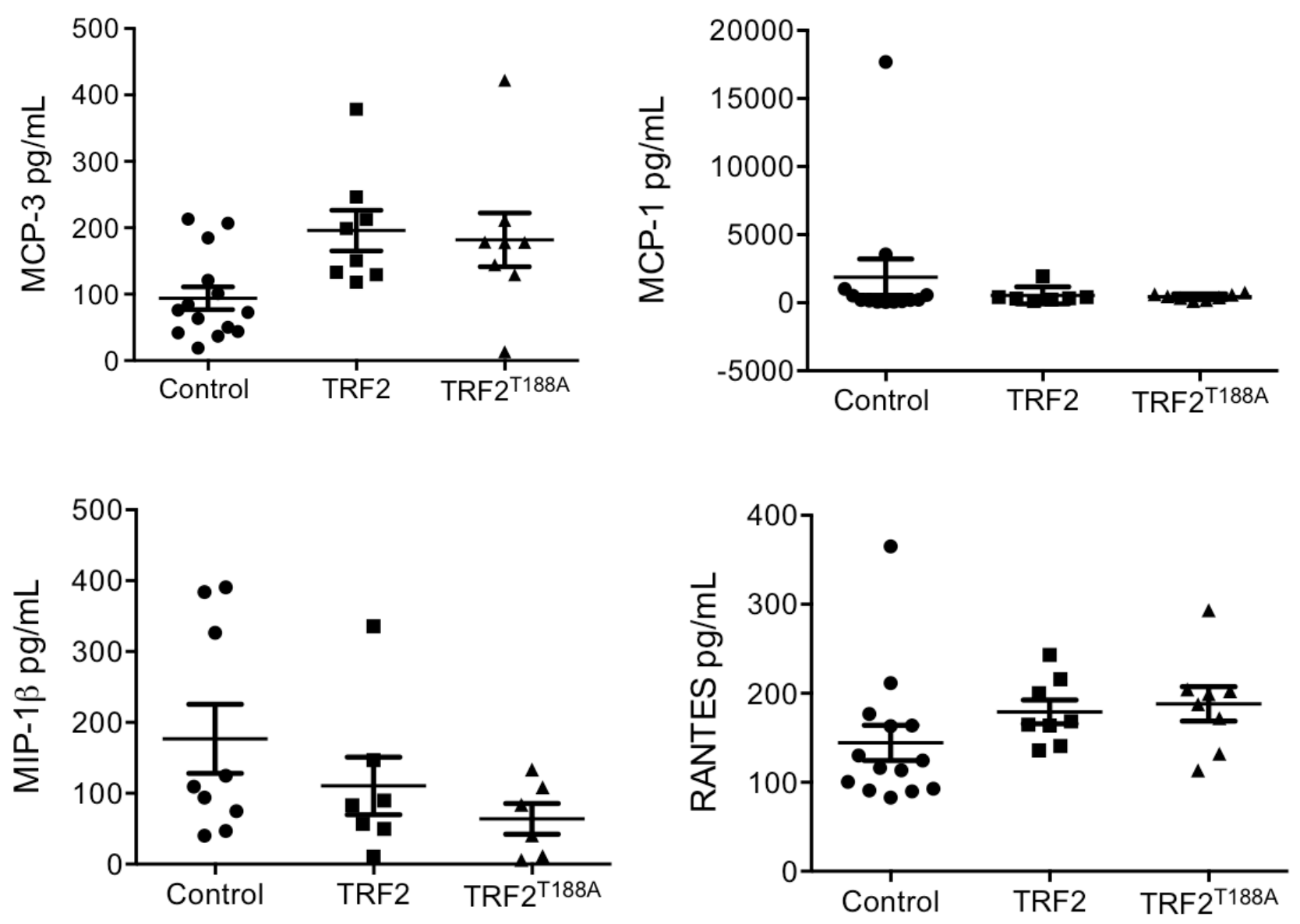

\section{Supplemental Figure 9}

Serum cytokines from experimental mice at $22 \mathrm{w}$ for MCP-3, MCP-1, MIP1 $\beta$ and RANTES after fat feeding from 6-22w. Data are means $\pm S E M, n=8-15$. 

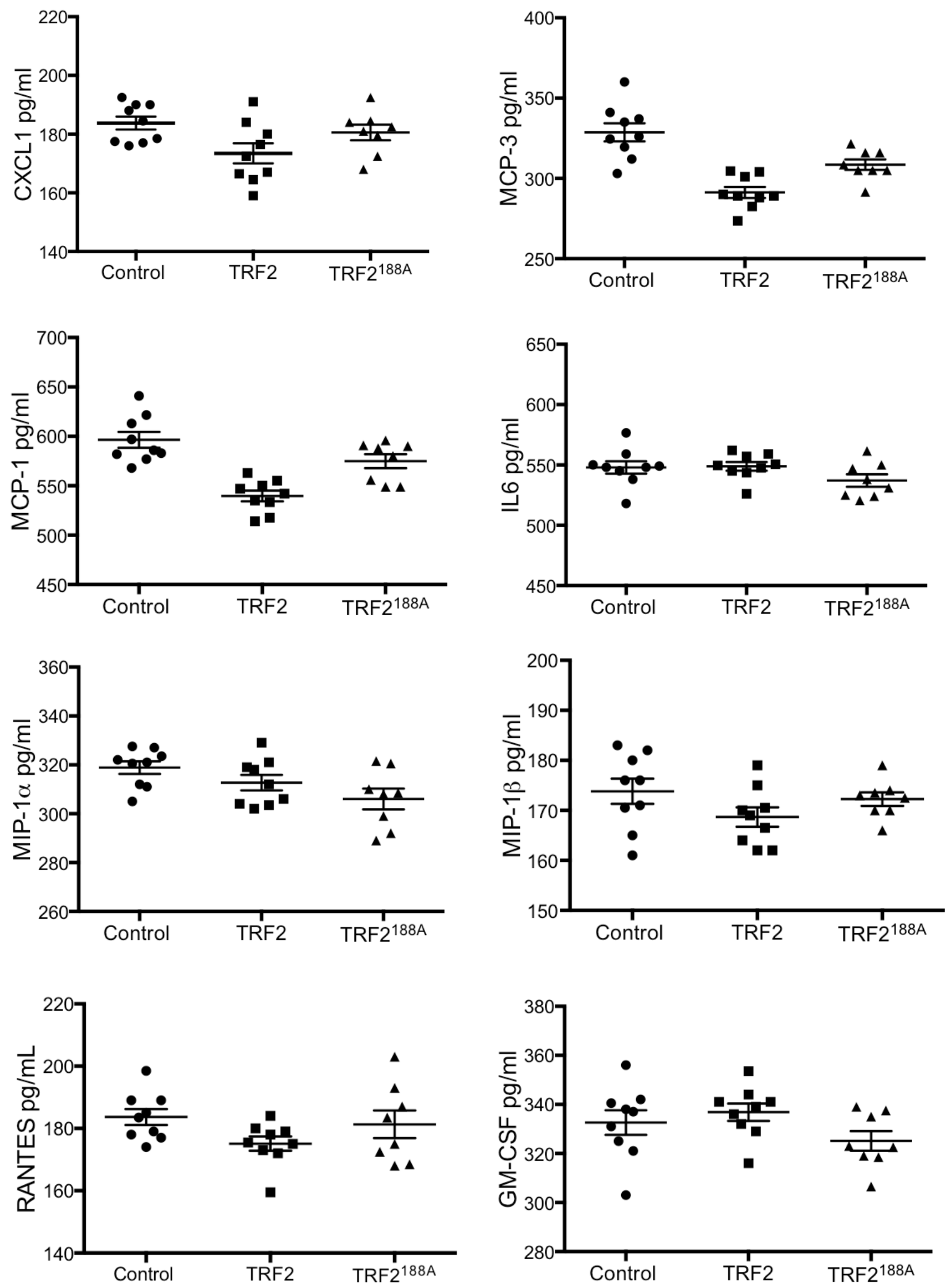

Supplemental Figure 10

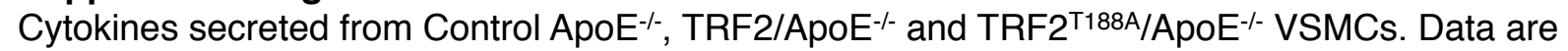
means \pm SEM. $n=8-10$. 


\section{Supplemental References}

1. Mahmoudi M, Gorenne I, Mercer J, Figg N, Littlewood T, Bennett M. Statins use a novel nijmegen breakage syndrome-1-dependent pathway to accelerate DNA repair in vascular smooth muscle cells. Circ Res. 2008;103:717-725

2. Hewitt G, Jurk D, Marques FD, Correia-Melo C, Hardy T, Gackowska A, Anderson R, Taschuk M, Mann J, Passos JF. Telomeres are favoured targets of a persistent DNA damage response in ageing and stress-induced senescence. Nat Commun. 2012;3:708

3. Mercer J, Figg N, Stoneman V, Braganza D, Bennett MR. Endogenous p53 protects vascular smooth muscle cells from apoptosis and reduces atherosclerosis in apoe knockout mice. Circ Res. 2005;96:667-674

4. Gorenne I, Kumar S, Gray K, Figg N, Yu H, Mercer J, Bennett M. Vascular smooth muscle cell sirtuin 1 protects against DNA damage and inhibits atherosclerosis. Circulation. 2013;127:386-396 


\section{Circulation}

Vascular Smooth Muscle Cell Senescence Promotes Atherosclerosis and Features of Plaque Vulnerability

Martin Bennett, Julie Wang, Anna K. Uryga, Johannes Reinhold, Nichola Figg, Lauren Baker, Alison Finigan, Kelly Gray, Sheetal Kumar and Murray Clarke

Circulation. published online September 28, 2015;

Circulation is published by the American Heart Association, 7272 Greenville Avenue, Dallas, TX 75231

Copyright (C) 2015 American Heart Association, Inc. All rights reserved.

Print ISSN: 0009-7322. Online ISSN: 1524-4539

The online version of this article, along with updated information and services, is located on the World Wide Web at:

http://circ.ahajournals.org/content/early/2015/09/28/CIRCULATIONAHA.115.016457

Data Supplement (unedited) at:

http://circ.ahajournals.org/content/suppl/2015/09/28/CIRCULATIONAHA.115.016457.DC1.html

Permissions: Requests for permissions to reproduce figures, tables, or portions of articles originally published in Circulation can be obtained via RightsLink, a service of the Copyright Clearance Center, not the Editorial Office. Once the online version of the published article for which permission is being requested is located, click Request Permissions in the middle column of the Web page under Services. Further information about this process is available in the Permissions and Rights Question and Answer document.

Reprints: Information about reprints can be found online at: http://www.lww.com/reprints

Subscriptions: Information about subscribing to Circulation is online at: http://circ.ahajournals.org//subscriptions/ 